\title{
Workers' Satisfaction vis-à-vis Environmental and Socio-Morphological Aspects for Sustainability and Decent Work
}

\author{
Abeer Elshater ${ }^{1, * \mathbb{D}}$, Hisham Abusaada ${ }^{2} \mathbb{D}$, Abdulmoneim Alfiky $^{1} \mathbb{D}$, Nardine El-Bardisy $^{1} \mathbb{D}^{\mathbb{D}}$, Esraa Elmarakby $^{3}$ \\ and Sandy Grant ${ }^{1}$ (D)
}

check for

updates

Citation: Elshater, A.; Abusaada, H.; Alfiky, A.; El-Bardisy, N.; Elmarakby,

E.; Grant, S. Workers' Satisfaction vis-à-vis Environmental and Socio-Morphological Aspects for Sustainability and Decent Work. Sustainability 2022, 14, 1699. https:// doi.org/10.3390/su14031699

Academic Editors: Baojie He, Ayyoob Sharifi, Chi Feng and Jun Yang

Received: 5 January 2022

Accepted: 29 January 2022

Published: 1 February 2022

Publisher's Note: MDPI stays neutral with regard to jurisdictional claims in published maps and institutional affiliations.

Copyright: () 2022 by the authors Licensee MDPI, Basel, Switzerland. This article is an open access article distributed under the terms and conditions of the Creative Commons Attribution (CC BY) license (https:// creativecommons.org/licenses/by/ $4.0 /)$.
1 Faculty of Engineering, Ain Shams University, Cairo 11517, Egypt; abdo.alfiky@eng.asu.edu.eg (A.A.); nardine.elbardisy@eng.asu.edu.eg (N.E.-B.); Sandy.grant@eng.asu.edu.eg (S.G.)

2 Housing and Building National Research Center, Giza 1770, Egypt; habusaada@yahoo.com

3 School of Science, Engineering and Environment, University of Salford, Salford M5 4WT, UK; esraa.elmarakby@eng.asu.edu.eg

* Correspondence: abeer.elshater@eng.asu.edu.eg

\begin{abstract}
This study examines worker satisfaction vis-à-vis outdoor places in terms of their environmental and socio-morphological aspects. Numerous studies have considered decent work as the eighth goal of sustainable development. However, it is worth investigating outdoor workers' satisfaction with a view to the practical design of the surrounding context that supports their work in outdoor places. Using bibliometric analysis, this study investigates possible approaches toward providing decent work in a public place in Cairo as a case study, focusing on outdoor workers' satisfaction. In the bibliometric analysis, this study used query settings in the Scimago database to search for manuscripts published in the previous five years. The result yielded 195 manuscripts that were filtered down to 50 manuscripts and then grouped using VOSviewr Software. Environmental noise and heat assessment analyses were performed using noise level measurements, remote sensing, and the Grasshopper platform. Further, we conducted an ethnographic study employing 77 participant observations. The results show that work hours and time affect worker satisfaction, as do environmental conditions, particularly noise and heat. However, unexpected findings from participant observation in this study do not accord with findings in other scholarly sources, where other observers find workers neither satisfied nor dissatisfied with the spatial morphology in the case study. Per this study, the alignment of worker satisfaction with convenient socio-morphological tangible elements of the workplace and with other environmental aspects should be attained in both specified replicable methods to engender decent work for outdoor workers.
\end{abstract}

Keywords: ethnographic research; land surface temperature; remote sensing; sound level measurement; sound pressure levels; urban heat islands

\section{Introduction}

Worker satisfaction and worker physical and mental well-being when working outdoors have led to an uptick in research interest in urban design and the provision of decent work. Environmental stresses, such as sound and heat, have been widely studied in the urban planning and design literature [1-3]. For decades, urban heat islands (UHI), which are urban areas significantly warmer than their surroundings because of human activities $[4,5]$, and sound pressure levels (SPLs) have been the most pressing worker challenges in creating sustainability [6]. Research has found environmental stress to result in a 5.3\% decrease in labor productivity [7] and found excessive heat and SPLs a substantial threat to outdoor workers [8-10].

Deleterious workplace effects and their impact on worker satisfaction, well-being, productivity, and performance have attracted considerable research attention [11,12], as 
have the community, connection, and wellness of workers (inside and outside of buildings) $[13,14]$. Consequently, UHI, noise exposure measurements, and other ecological design models that assess the impact of environmental stress on worker performance have emerged $[15,16]$. Outdoor workers in cities such as Accra, Ghana [2], and Guangzhou, China [8] are exposed to sound and heat stresses that affect their satisfaction, well-being, performance, and productivity.

This study tackles the challenges confronting urban area redevelopment projects with several outdoor workers, such as construction workers, street vendors, street workers, mechanics, and kiosk sellers. Generally, redevelopment plans focus on user satisfaction rather than the people who provide the services outdoors in arid climates [8,17]. Workplace studies have often overlooked the satisfaction of outdoor workers and the environmental factors that affect productivity.

Previous research has examined worker satisfaction through workplace locations [18], thermal response [8], thermal comfort [1], social workplace relationships [19], and working hours [20]. Nevertheless, few urban planning studies have considered environmental effects, such as UHI and SPL, in their designs to ensure decent outdoor work. To achieve "decent" work conditions, public spaces that encompass many outdoor workers need to be designed to ensure economic productivity $[15,16,21]$. However, few studies linking decent work conditions and workers' satisfaction have been conducted. Thus, the link between these factors and decent work should be discussed to help fill the gaps in this relationship. Moreover, no standards have been set for decent work conditions in Egyptian cities, and no studies on these cities have suggested theoretical models to examine the environmental influences that affect worker productivity and satisfaction.

Several alternative methods have been suggested to solve outdoor worker problems. For example, one of the UN's Sustainable Development Goals (SDGs), SDG 8, aims to achieve "full and productive employment and decent work for all women and men by 2030" [22]. However, the main problem is that urban research has paid little attention to this specific goal [3], and the studies focused on SDG 8 and worker satisfaction have offered no methodologies to ensure comfortable outdoor urban workplaces in arid areas. Hence, it has become essential to develop possible urban scenarios that could ensure decent work conditions for outdoor urban workers in arid regions.

A new design approach is needed that focuses on the different activities conducted by outdoor workers. Thus, this paper abstracted the UHI and SPL factors from previous studies, built a model to test worker satisfaction based on these factors, and explored the methods urban planners and designers could use to ensure better UHI and SPL work conditions in Al-Weili, Cairo, Egypt.

This study had two main aims. First, a model was developed that can assist urban planners in ensuring decent work conditions in public places. Second, this study investigated safe and convenient working methods that could improve worker productivity in arid regions. Specifically, on the basis of a case study in Cairo, Egypt, the UHI and SPL were examined to determine the levels needed to ensure outside worker well-being and productivity.

A multi-method design was applied to examine the impacts of the factors influencing outdoor worker productivity, satisfaction, and decent work conditions. Then, a case study was conducted for which field measurements were taken. A sound level meter was used to make sound level measurements (SLMs) and measure sound tolerance levels and sound pressure; in addition, remote sensing and the Grasshopper and Ladybug plugins were used to measure heat exposure and UHI effects on workers' satisfaction. Based on participant observations in the selected area, an ethnographic study on the distribution of worker activities in the outdoor environment was conducted, whereafter the participants completed an online survey to determine the factors affecting worker satisfaction. Finally, the contextual factors related to UHI and NE affecting outdoor workers were investigated.

The first main contribution of this study is the identification of the factors affecting outdoor worker satisfaction in an urban space in Cairo, Egypt, which provides a valuable 
resource to urban planners and urban designers to ensure outdoor space designs that consider the decent work conditions outlined in SDG 8. This study also provides holistic perspectives on SDG 8 that can be linked to various dimensions, such as sociability in the work environment and economic productivity.

The remainder of this study is organized as shown in Figure 1. Section 2 reviews relevant literature on decent work conditions and the worker satisfaction factors in urban spaces (urban environment, urban planning, and urban design). Section 3 details the multi-method design used for the selected case study in Al-Weili District, Cairo, Egypt, which involved a UHI and SPL environmental analysis, as well as an ethnographic study on worker satisfaction in urban spaces, based on previous environmental measurements. Sections 4 and 5 discuss the case study results. Section 6 discusses the implications of the key findings for developing decent work conditions in outdoor places and concludes the paper.

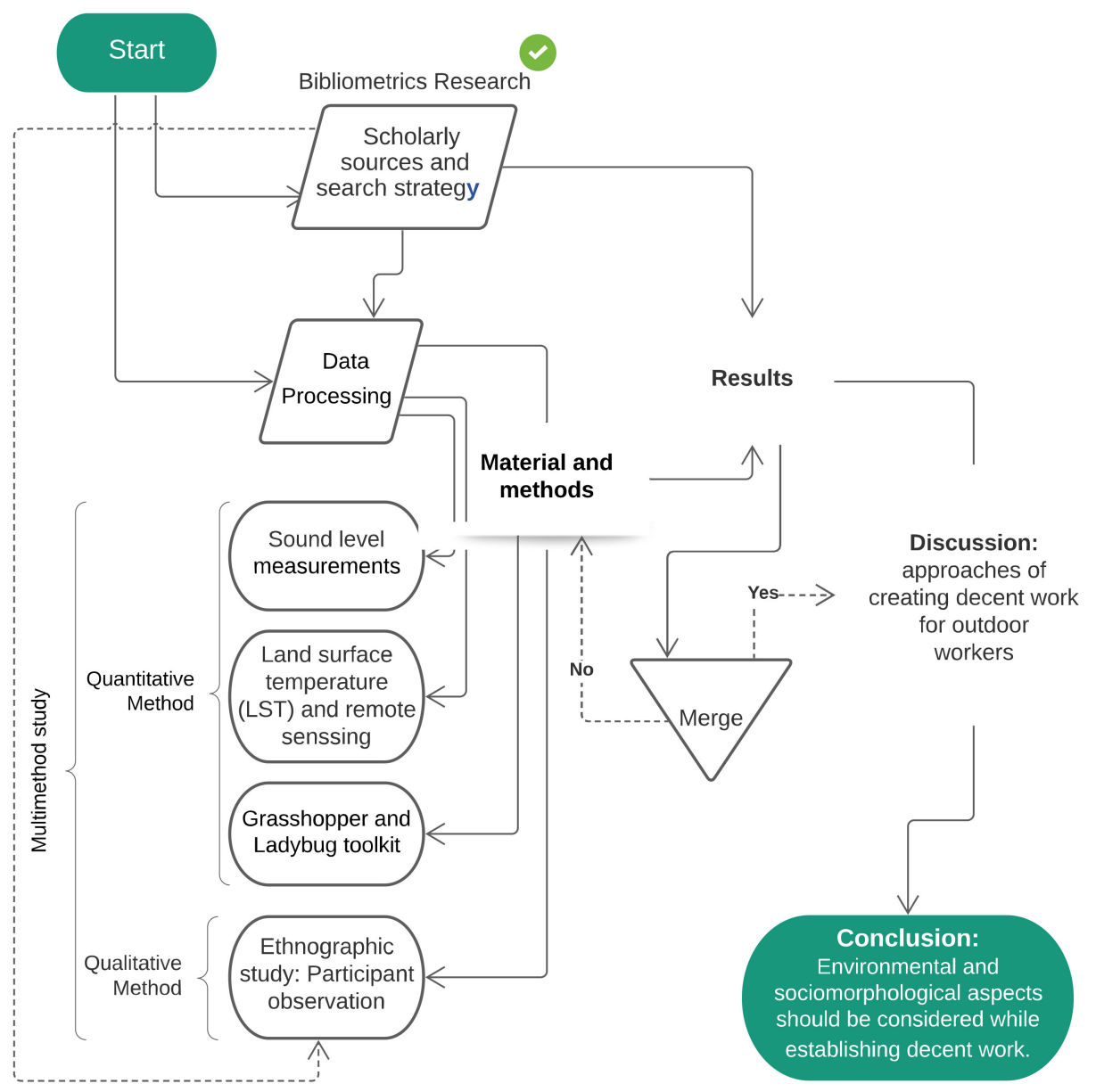

Figure 1. Research design.

\section{Background and Topical Literature Review}

\subsection{Scholarly Sources and Search Strategy}

A bibliometric search of related work was performed from late 2020 to late 2021 to identify the literature on decent work in urban studies and relevant areas of knowledge and worker satisfaction. We sought to determine the factors that influence worker satisfaction and productivity as addressed by diverse fields of knowledge such as urban studies, social sciences, and work management.

The search strategy was performed in two phases. The first phase was a random search using keywords (i.e., urban heat islands (UHI), noise, workplace, decent work, and worker satisfaction). The inclusion criteria included reports written in English and 
published during the past five years by organizational or governmental institutions that tackle works and sustainability affairs, which yielded five technical reports, issued by the International Labour Organization (ILO) [12,23], Kleinfelder [24], the Occupational Safety and Health Administration [25], the United States Department of Labor, and the United Nations [22]. Data mining was then conducted on the Scimago Journal and Country Rank database (SJR). The scope of the search in SJR was limited to the present authors' area of expertise in environmental science, management, and social sciences.

In the bibliometric data curtain, we searched the SJR database using the keywords "climate", "decent work", "labor", "noise", "performance", "productivity", "satisfaction", "sound", "surface temperature", "urban heat island", "workplaces", and "workers", which were in the three areas of expertise published from 2016 to 2021. Search results had one or more keywords in the title, abstract, and/or keywords. Articles were selected according to the relevant ones published by highly indexed journals in the first quartile (Q1) and second quartile (Q2) based on the impact factor of the journal and citations, which yielded 195 manuscripts. The results excluded materials from journals from outside of environmental science, management, and social sciences, such as the Journal of Applied Physics Reviews. Furthermore, the selection excluded manuscripts from the subject areas of physics, computer science, and plant science. The results yielded 50 manuscripts. To examine the results obtained, this study used VOSviewer Software to group the topics into three groups of topics, with a minimum cluster size of 1 and a repulsion of 1 . All the detailed findings for these three groups are illustrated in 'data availability statement'.

\subsection{Interpreting the Collected Materials}

Driven by the SGD 8 aim for decent work conditions for all workers, this section reviews the concepts found to affect proper work conditions, such as UHI and SPL.

The UN's SDGs have 17 goals, each of which has several targets assigned [12,23]. This study mainly focuses on SDG 8, which aims to "promote sustained, inclusive and sustainable economic growth, full and productive employment, and decent work for all" [22] (p. 15). Associated with this 2030 development agenda are 12 targets [26,27]. One is to achieve a higher level of economic productivity by broadening worker competencies, transforming technologies, and encouraging innovation [28,29]. The definitions for decent work conditions vary from one country to another; however, the basic definition of this goal and its targets is the provision of various possibilities for women and men to achieve good and productive work in an environment that promotes liberty, fairness, security, and human dignity [22].

Nine main characteristics have been identified as contributing to the idea of decent work: (1) work stability and security; (2) adequate compensation and productive work; (3) reasonable work hours; (4) balancing work, (5) family, and (6) personal life; (7) equal opportunity and treatment; (8) a safe work environment; (9) and social security. Previous studies have also concluded that good outdoor working environments that consider temperature or noise levels can result in higher worker productivity and satisfaction $[8,12,30]$.

Few comprehensive outdoor working environment studies have focused on worker satisfaction [2,31,32]. However, the few studies that have considered satisfaction factors have identified physical factors, such as building and space design [33], and non-physical factors, such as temperature [8], noise [2], and air quality [17]. In addition, studies have found suitable outdoor workplace environments to be convenient, flexible, and visually appealing to the employee [34] to encourage worker concentration, a sensory and physical connection to their work roles, and engagement with the context and their peers [35].

Of the main environmental factors, noise, has been found to be a significant cause of worker distraction in both indoor and outdoor workplace settings $[9,19,36]$. Excessive noise has been found to lead to a decrease in productivity, an increase in accidents and job-related stress, and be the source of the indecent treatment of workers [37]. Employee productivity has also been found to be better in natural light and good air quality in the workplace [38,39]. 
Other significant environmental factors affecting human health and productivity are air temperature and heat tolerance [40], UHI [8], building and structure surfaces [41,42], air pollutants [43], urban form [44], and the increased use of air conditioners in urban areas [6]. Notably, concerns have been expressed about the effects of UHI and air quality on communities [45]. Some studies have examined the effect of UHI on human activities in public spaces from various perspectives, such as the urban economy, society, and nature [42], and have highlighted the importance of considering factors such as UHI that affect worker productivity [8].

However, several questions on decent work conditions remain to be addressed. The review of bibliometrics of SJR shows few studies as having holistically or directly addressed environmental issues or the effect these factors have on worker productivity (Figure 2). The bibliometric analysis shows that decent work in literature was not directly discussed in the engineering or time management areas of knowledge, nor was it even linked to worker satisfaction or urban morphology. Thus, the question is how best to define the parameters that affect worker satisfaction and decent work.

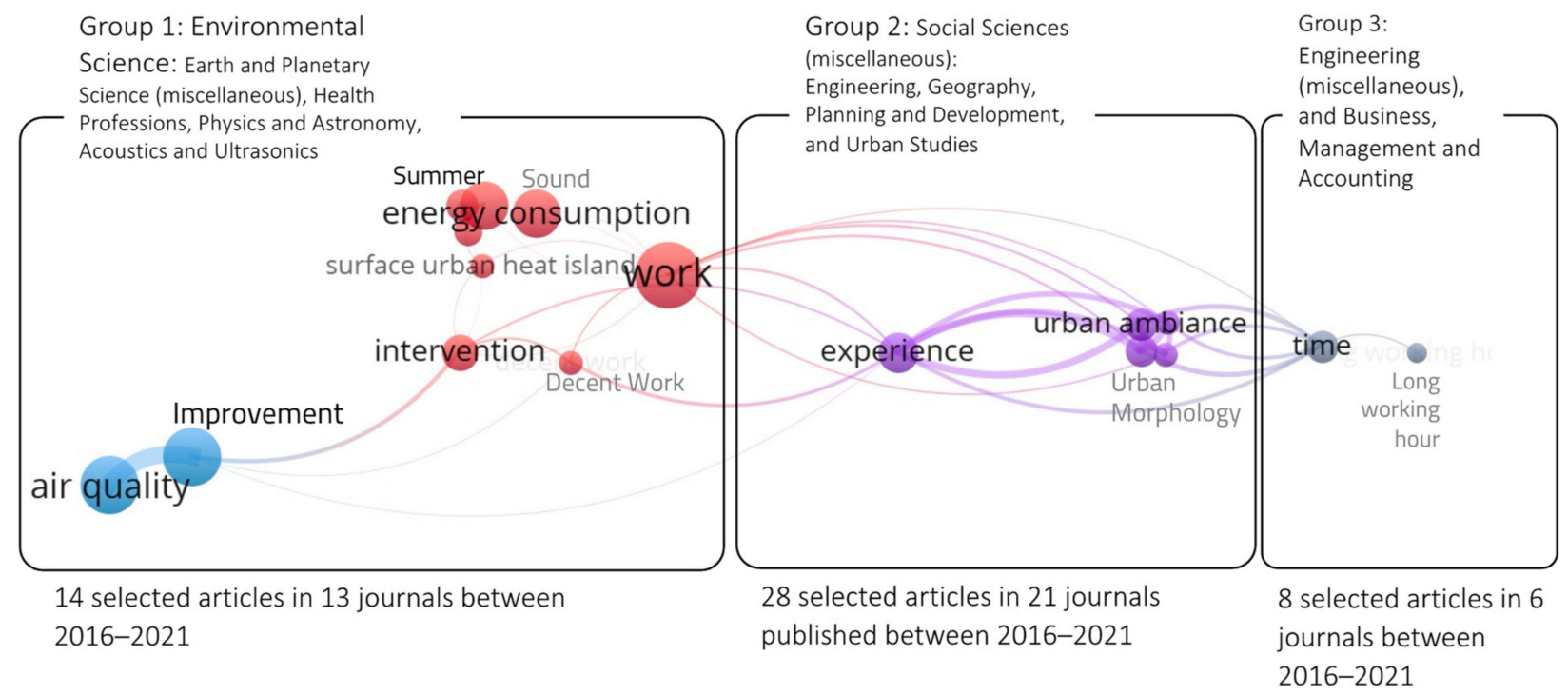

Figure 2. The bibliometric source mapping based on SJR database during 2016-2021 and analyzed by VOSviewer. The three groups are displayed in 'data availability statement' section.

This study is unique as no studies have specifically addressed the contextual environmental and design effects on worker productivity. However, Xia et al. [21] found that a 14-day heat wave that resulted in severely heated UHI in Nanjing, China, caused total economic losses of approximately CNY 27 billion.

Thus, this study goes some way toward filling the gap in the literature on the contextual design factors for workers in public spaces. Although previous studies have identified several factors that affect worker productivity and the provision of a decent work environment [11], additional studies are needed to understand more completely the key tenets of the effects of the built environment on decent work conditions.

\section{Data Processing and Four Measurements}

This research study is focused on the SDG 8 requirement for decent work conditions and outdoor workers' satisfaction with their workplace, with a particular emphasis on Egypt. This section reviews the study design and data analysis. To identify the workplace environmental factors that influence worker performance, this research study used a multimethod design. First, environmental UHI and SLP analyses were conducted, whereafter, a qualitative ethnographic study was conducted on the basis of participant interviews and an online survey $[46,47]$. These methods provided a holistic perspective for contextual 
design investigations into UHI, sound pollution, and chaos and their effects on decent work environments.

\subsection{Case Study}

To verify the research questions, a case study was conducted in Al-Weili District, Cairo (Figure 3). This district is divided into neighborhoods or Shiyahka, according to Egyptian urban structure. Communally, the citizens call the entire district Abbassia. The study area site boundaries were selected on the basis of the outdoor environment worker activity distributions.

An area was selected that had diverse outdoor worker activities. The reason this area was selected was that it was close to the researchers' institutions, which allowed for easier data collection because of a familiarity with the context. The fieldwork investigation found that the selected site included several types of workers, which assisted in identifying the various challenges affecting worker productivity. The main limitations, however, were the availability of data in this district in the indexed urban studies journals, such as the Web of Science and Scopus databases. Thus, the field data were validated using the following methods.

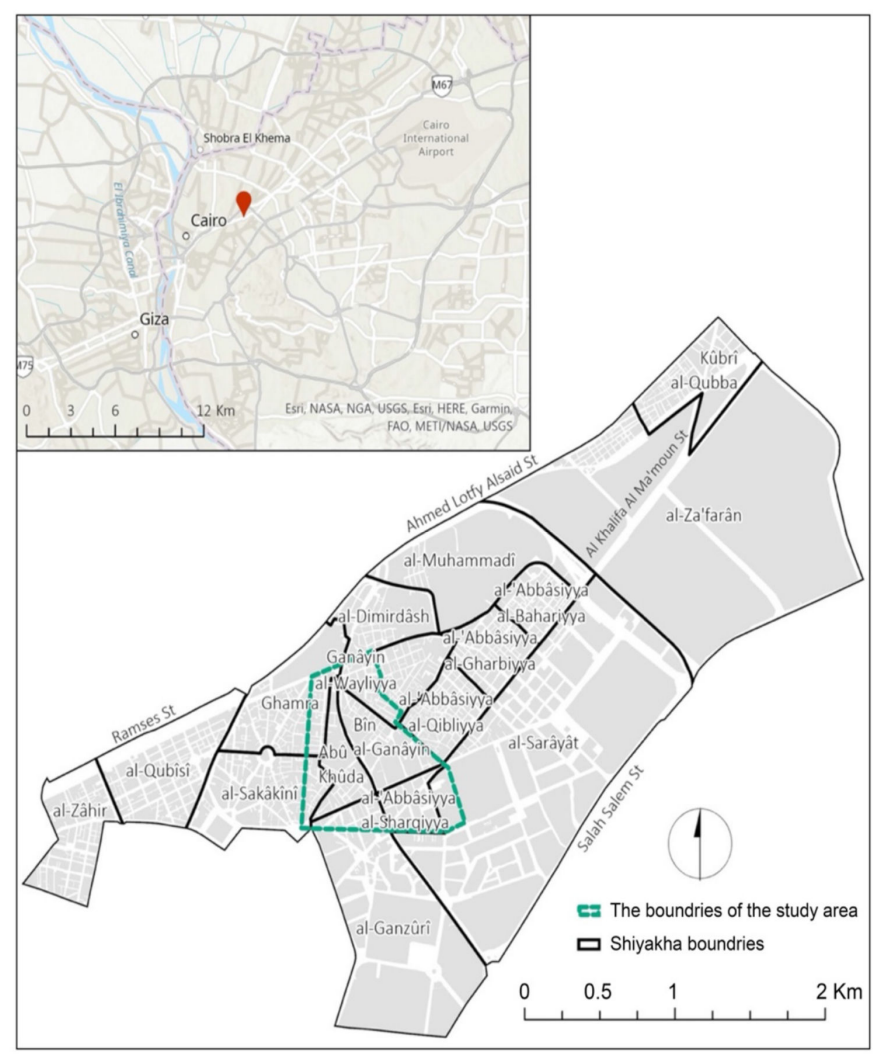

Figure 3. Study area in the Al-Weili District, Cairo.

\subsection{Noise Measurements and Apparatus}

Several environmental noise measures have been previously identified [2,32,35]. Before starting the field measurements, the information required to determine the noise sources and at what times the sources were operating were identified. SLM and sound level data in the exposed worker outdoor locations were collected during both typical and atypical shifts (noise sources, activities, shift length, etc.), for which three apparatuses were used: a BandK 2245 Sound Level Meter, a microphone, and a BandK 4321 Calibrator.

To ensure the presence of workers at the selected site, the SPLs and sound variation frequencies were measured over a working day in Cairo on 6 June 2021 (Table 1). SLM was used to measure SPLs at 3 locations (MOL) for 5 min each [32]. These noise M0Ls 
were selected on the basis of the maximum distribution zones for the vendors and workers outside of the buildings (Figure 4). SLM follows the decibel (dB) scale and adopts the standard that the sound level in residential areas should not exceed $50 \mathrm{~dB}$ [25].

Table 1. Sound measurement location settings.

\begin{tabular}{llllll}
\hline Measurement (M0L) & Latitude & Longitude & Start Time & End Time & Elapsed Time \\
\hline M03 & $30^{\circ} 3^{\prime} 55.116^{\prime \prime} \mathrm{N}$ & $31^{\circ} 16^{\prime} 37.2648^{\prime \prime} \mathrm{E}$ & $7: 02: 30 \mathrm{PM}$ & $7: 07: 30 \mathrm{PM}$ & $0: 05: 00$ \\
M04 & $30^{\circ} 3^{\prime} 58.9674^{\prime \prime} \mathrm{N}$ & $31^{\circ} 16^{\prime} 16.611^{\prime \prime} \mathrm{E}$ & $7: 12: 08 \mathrm{PM}$ & $7: 17: 08 \mathrm{PM}$ & $0: 05: 00$ \\
M05 & $30^{\circ} 3^{\prime} 49.8276^{\prime \prime} \mathrm{N}$ & $31^{\circ} 16^{\prime} 22.3536^{\prime \prime} \mathrm{E}$ & $7: 18: 59 \mathrm{PM}$ & $7: 23: 59 \mathrm{PM}$ & $0: 05: 00$ \\
\hline
\end{tabular}

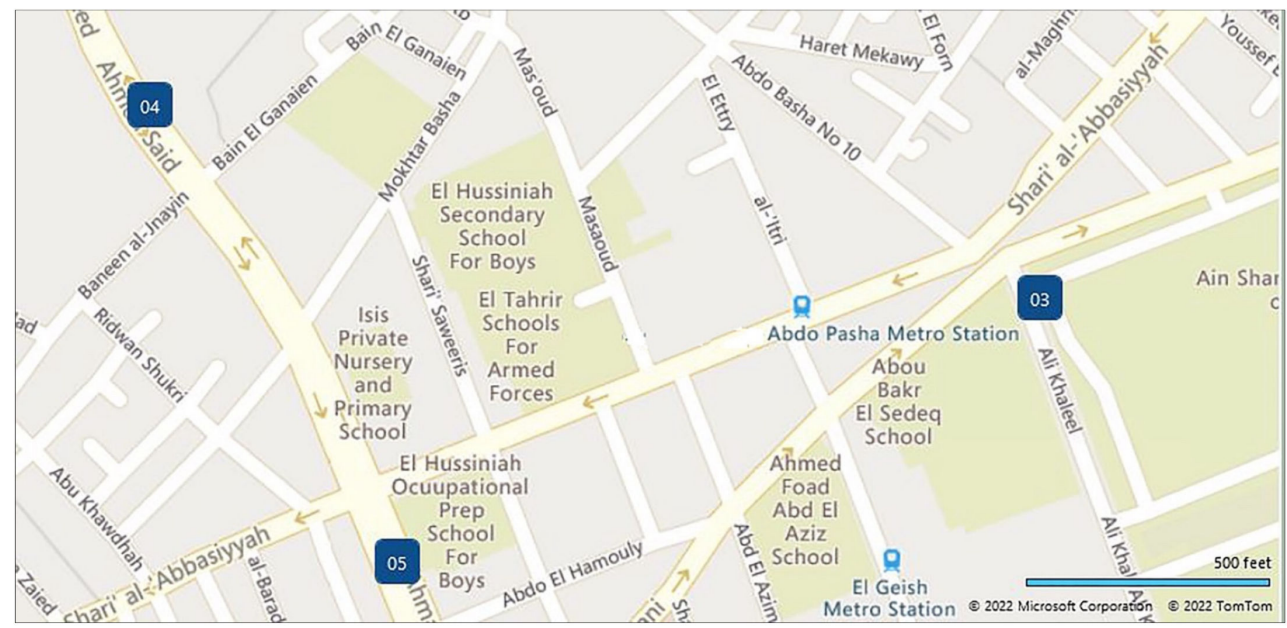

Figure 4. Three Ahmed Said Street sound measurement locations (03, 04, and 05).

\subsection{Macro-Scale UHI Investigation}

Although several satellite images are available to identify UHI [48], this research study used Landsat 8 images for the context of Ahmed Said Street on 6 June 2021, which had a spatial resolution of $30 \mathrm{~m}$. Table 2 provides details of the analyzed satellite image. The analysis was conducted using geographical information systems (GIS) software. Landsat 8 was utilized to create thermal pictures because it has a resolution of 15-100 m, depending on the type of data saved, and provides a regular 16-day observation interval. Further, Landsat 8 provides images with a resolution appropriate for the research area $(30 \mathrm{~m})$. In addition, it offers a regular snapshot of the Earth's surface. A thermal infrared sensor (TIRS) and an operational land imager (OLI) are the satellite's two sensors [49].

Table 2. Landsat image metadata details.

\begin{tabular}{|c|c|c|c|c|c|c|c|c|}
\hline Satellite & Sensor & $\begin{array}{l}\text { Acquisition } \\
\text { Date }\end{array}$ & GMT $^{1}$ & $\begin{array}{l}\text { Cairo Local } \\
\text { Time }\end{array}$ & $\begin{array}{l}\text { Path and } \\
\text { Row }\end{array}$ & $\begin{array}{l}\text { Spatial } \\
\text { Resolution }{ }^{2}\end{array}$ & Cloud Cover & $\begin{array}{l}\text { Temp } \\
\text { Measured Unit }\end{array}$ \\
\hline Landsat 8 & OIL_TIRS & 6 June 2021 & $8: 23: 45$ & $10: 23: 45$ & $176 / 39$ & 100 & 3.80 & ${ }^{\circ} \mathrm{C}$ \\
\hline
\end{tabular}

To begin processing the image with TIRS, Equations (1) and (2) were used to perform the radiometric correction. To assess the heat exposure, the conversion to the top of atmosphere (TOA) radiance was used [50], with a focus on Band 10 [Thermal Infrared (TIRS) 1] and Band 11 [Thermal Infrared (TIRS) 2].

$$
\mathrm{L}_{\lambda}=\left(\mathrm{M}_{1} \times \mathrm{Q}_{\mathrm{cal}}\right)+A_{l}
$$

where: $L_{\lambda}$ is total spectral radiance; 
$\mathrm{M}_{1}$ is band-specific multiplicative rescaling factor from the metadata (RADIANCE_ MULT_BAND_x, where $\mathrm{x}$ is the band number);

$\mathrm{M}_{1}$ is band-specific additive rescaling factor from the metadata (RADIANCE_ADD_ BAND_x, where $x$ is the band number: 9 and 10) and

$\mathrm{Q}_{\text {cal }}$ is quantized and calibrated standard product pixel values.

$$
\mathrm{T}_{\mathrm{k}}=\frac{\mathrm{K}_{2}}{\mathrm{~L}_{\mathrm{n}}\left(1+\frac{\mathrm{K}_{1}}{\mathrm{~L}_{\lambda}}\right)}
$$

$\mathrm{T}_{\mathrm{k}}=$ At-satellite brightness temperature in Kelvin degrees

$\mathrm{L}_{\lambda}=$ TOA spectral radiance;

$\mathrm{K}_{1}=$ band-specific thermal conversion constant from the metadata $\left(\mathrm{K}_{1}\right.$ CONSTANT_BAND_x, where $x$ is the band number: 10 or 11) and

$\mathrm{K}_{2}$ = band-specific thermal conversion constant from the metadata $\left(\mathrm{K}_{2}\right.$ CONSTANT_BAND_x, where $\mathrm{x}$ is the band number: 10 or 11)

Equation (3) was used to convert $\mathrm{T}_{\mathrm{k}}$ from Kelvin to degree Celsius.

$$
\mathrm{T}_{\mathrm{C}}=\mathrm{T}_{\mathrm{k}}-273.15
$$

Land surface temperatures can be affected by error ratios because of the calibration noises in Landsat 8 Band 11 and the reliance on Band 11 measurements [16,51,52]. Hence, the average of the two bands' mean brightness temperatures was used as the average temperature. The NIR and the red bands were used to determine the normalized difference vegetation index (NDVI) [53]

$$
\begin{gathered}
\text { NDVI }=(\operatorname{NIR}(\text { Band } 5)-\operatorname{Red}(\text { Band } 4)) /(\operatorname{NIR}(\text { Band } 5)+\operatorname{Red}(\text { Band } 4)) \\
P_{\mathrm{t}}=\frac{\text { NDVI }- \text { NDVI min. }}{(\text { NDVImax. }- \text { NDVImin. })^{2}}
\end{gathered}
$$

The percentage foliage or percentage vegetation signified the percentage of vegetation on the vertical projection surface relative to the overall surface. From the results of surface emissivity, the land surface temperature was calculated [54]. The locations that were one or more standard deviations above the mean temperature were classified as UHI, where the value for $\mu$ was the mean land surface temperature and $\sigma$ was the standard deviation.

$$
\mathrm{e}=0.004 \times \mathrm{P}_{\mathrm{t}}+0.986
$$

From the results of the surface emissivity (e), the land surface temperature (LST) was calculated using Equation (7) [54]:

$$
\mathrm{LST}=\frac{\mathrm{T}_{\mathrm{kav}}}{\left[1+\left(\left(\frac{\mathrm{M}_{10} \times \mathrm{T}_{\mathrm{k}}}{\rho}\right) \operatorname{In} \mathrm{e}\right)\right]}
$$

where $\mathrm{T}_{\text {kav }}=$ mean brightness temperature;

$\mathrm{M}_{10}=$ Landsat Band 10;

$\mathrm{T}_{\mathrm{k}}=$ at-satellite brightness temperature in Kelvins;

$\rho=\left(h^{*}(c / 6)\right.$, where $h$ is Planck's constant $\left(6.626 \times 10^{-34} \mathrm{~J} \mathrm{~s}\right), c$ is the velocity of the light $(2.998 \times 108 \mathrm{~m} / \mathrm{s}) 0.01438,6$ is the Boltzmann constant $\left(1.38 \times 10^{-23} \mathrm{~J} / \mathrm{K}\right)$, and

$\mathrm{e}=$ emissivity.

$$
\mathrm{UHI}=\mathrm{T} \geq 1 \sigma+\mu
$$

The locations that were one or more standard deviations above the mean temperature were classified as UHI, where the value for $\mu$ was the mean land surface temperature and $\sigma$ was the standard deviation [24]. 


\subsection{Micro-Scale UHI Investigation}

There are now several methods and techniques available to measure heat tolerance in outdoor environments [55-57]. This study used Rhinoceros software (version 6.0 copyrights) for the modeling and construction template to determine the heat exposure and used the Grasshopper and Ladybug toolkit as the engine to deal with the 3D geometry and simulation parameters. As in previous research, Grasshopper was utilized to produce the generative algorithms needed to generate the 3D geometry for the case study $[58,59]$. The data entry for this software comprises individual components that can be dragged and dropped on a "canvas", whereupon the outputs for one component are connected to the inputs of another component.

In this study, the Grasshopper and Ladybug plugins were used for the environmental analysis and the measurement of outdoor thermal comfort (Table 3), and a weather file was imported into the program. The file used in the case study was developed from the Egyptian Typical Meteorological Year. The expected results from the microscale human outdoor heat exposure platform were used to build the main model and determine the simulation parameters. A simulation was then conducted to draw the sun path diagram and conduct the sun-hour and wind analyses on 6 June 2021.

Table 3. Weather file used for the simulation.

\begin{tabular}{ll}
\hline & Cairo \\
\hline Weather file & EGY_Cairo.Intle.Airport.623660_ETMY.epw \\
Latitude/longitude & 30.13 -degree north, 31.4-degree East \\
Elevation (m) above sea level & 74 \\
Data source & ETMY 623660 WMO station number \\
\hline
\end{tabular}

Using the Grasshopper platform definition (Figure 5), a platform for Ahmed Saeed Street was built as a three-dimensional digital model. Four-phase environmental analysis was then conducted using the Ladybug toolkit. In the first phase, the three-dimensional digital model was simulated using Rhinoceros software. To facilitate the data collection for the building heights, it was assumed that the building heights ranged from 1 to 2 stories or $6 \mathrm{~m}$ in height and from 3 to 5 stories or $12 \mathrm{~m}$ in height. Buildings above 5 stories were considered to be $15 \mathrm{~m}$ in height. In the second phase, the research set model in Grasshopper was used for the simulation. The third phase comprised the generation of the output diagram, and in the fourth phase, the charts and diagrams were compared with the output results.

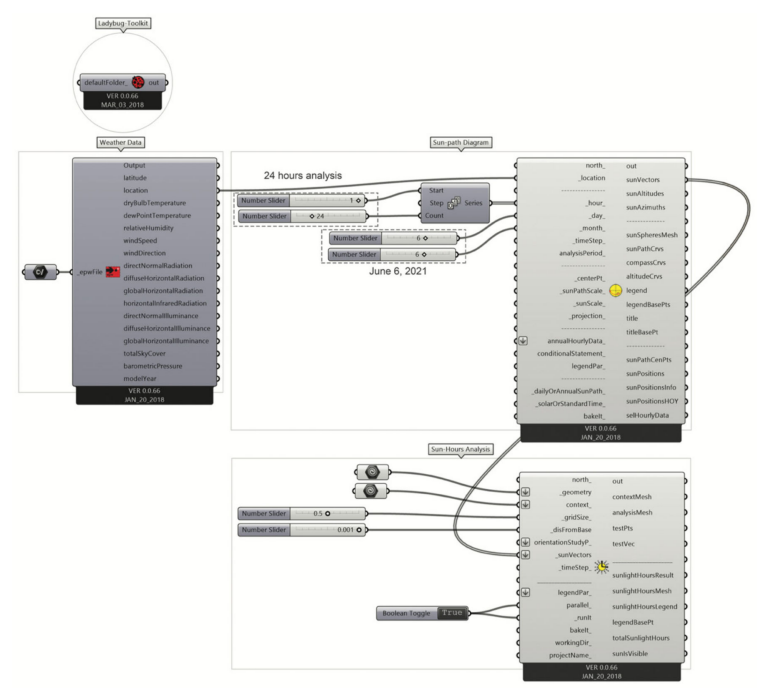

Figure 5. Grasshopper definition. 


\subsection{Qualitative Participant Observation: Participant Recruitment}

This study used a participant observation ethnographic research technique (peopled ethnography) to investigate worker satisfaction impressions and improve the existing outdoor environment for outdoor workers. The observation involved both subjective participant observations and objective observations; the outdoor workers were not aware that they were being observed.

Qualitative participant observation data analysis was applied instead of a worker survey for two reasons. First, it was difficult to gain direct contact with the workers on the site, and second, this data collection required professional communication skills, which may not have been possible from worker survey data. True objectivity, however, was an ideal, not a reality, as the participants realized.

The purpose of the participant observations was to assess the impact of the physical environment on satisfaction, which can affect productivity. A sample of voluntary participants with at least a two-year familiarity with the site was selected from the institutions near the study area. The selected participants were required to observe the working community to gain an understanding of their satisfaction with the workplace environment. The authors of this work invited students in their classes during the semester of Spring 2021 as volunteers to be part of data collection. The participant invitation criteria were based on including a minimum age of 20 years, an awareness of the workers' communities, and a familiarity with the site based on their regular visits during their university study. These criteria ensured that subjective data could be collected through personal interactions with the participants as well as access to the working community. Finally, 77 participants out of the 123 students invited in this volunteer task, that is, 37 architects, 23 landscape architects, 8 urban designers, 7 urban planners, and 2 mechanical and civil engineering participants-were selected, each of whom observed the site for $2 \mathrm{~h}$ (weighted average).

The participants were asked to observe the workers working outdoors, such as street and road workers, vendors, remote vending shops, kiosk sellers, building and construction workers, garbage/trash collectors, traffic officers, security guards, sellers of ready-to-eat products, and mechanics. The participants were asked to pick points on the map where they could see the workers on site (Figure 6).

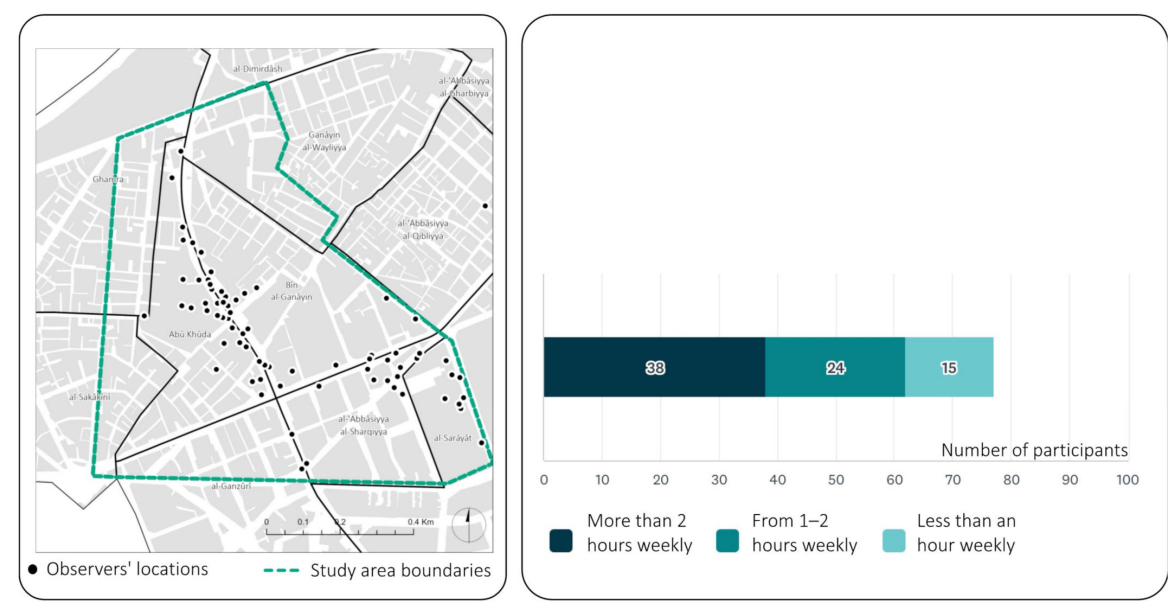

Figure 6. Places of participant observation where each dot represents the location of an observation by one of the participants.

As the participant observation yielded data that could have been difficult to analyze to determine the quality of the outdoor work environment, after their observation period, each participant completed a structured online survey powered by SurveyMonkey on their observations and experience. The survey had 3 groups of questions with 13 questions (The survey questions can be reached using the link. Available online: https:/ / www.research. net/r/NRRHKBC (accessed on 20 February 2021). 
The first question group consists of six questions. This set of questions asked participants for general information regarding their academic background, the location from where they observed the outdoor workers and the types of workers they observed, and a general question focusing on the duration of the site observation. Building upon our bibliometrics analysis derived from the SJR database, the second group of questions had four questions focusing on overall satisfaction, the decent outdoor environment (DOE) [40], socio-morphological tangible characteristics (SMTC) [33,36], and the response indicators to the intangibles (RII) [60]. The third group of questions asked the participants three questions. The first was about the factors they felt affected the affective atmosphere as visitors to the sites. The second was how likely the observers were to recommend a business at the site. The last question in this group was whether they had any other comments about the site condition and its effect on worker productivity.

The participants were guided by their prior experiences in how they viewed the context and the workers. Competent observers were expected to maintain a critical selfreflexivity that allowed them to understand how the data-gathering research could be influenced; thus, the participants needed to remain detached as observers to the ways of life and the working environment perspectives. However, this process was time-consuming, which meant that the data collection needed to be extended from three months to a year

\section{Results}

\subsection{Sound Pressure Results}

The SLM results in Table 4 indicate that the noise levels were higher in all 3 selected locations (equivalent continuous sound level $(\mathrm{Leq})=67.88 \mathrm{~dB}$ ) than the required level of $50 \mathrm{~dB}$ for residential areas on the decibel scale [45]. The field observation confirmed that this noise level was because of traffic, workers, and residential activities. Caution should be taken with generalizing the findings that higher noise levels decrease the productivity and performance of workers.

Table 4. Sound measurements in the three selected points.

\begin{tabular}{|c|c|c|c|c|c|c|c|c|c|}
\hline \multirow{2}{*}{ Measurement Data } & \multicolumn{5}{|c|}{ Weather Condition ${ }^{1}$} & \multirow{2}{*}{$\begin{array}{c}\text { Leq } \\
\text { dBA }\end{array}$} & \multirow{2}{*}{$\begin{array}{r}\text { L90 } \\
\text { dBA }\end{array}$} & \multirow{2}{*}{$\begin{array}{r}\mathrm{L} 50 \\
\mathrm{dBA}\end{array}$} & \multirow{2}{*}{$\begin{array}{r}\text { L10 } \\
\text { dBA }\end{array}$} \\
\hline & WS & WD & Temp. & Humidity I & & & & & \\
\hline M03 & & & & & & 67.88 & 69.69 & 63.4 & 59.44 \\
\hline M04 & $3.5 \mathrm{~m} / \mathrm{s}$ & NE & $26{ }^{\circ} \mathrm{C}$ & $57 \%$ & 0 & 74.81 & 75.26 & 68.63 & 63.68 \\
\hline M05 & & & & & & 75.54 & 77.43 & 69.99 & 64.55 \\
\hline
\end{tabular}

${ }^{1} \mathrm{WS}=$ wind speed, $\mathrm{WD}=$ wind direction, Temp. = temperature, $\mathrm{H}=$ humidity, $\mathrm{P}=$ precipitation, $\mathrm{dBA}=$ Decibel average, Leq = equivalent continuous sound level.

The M03 field measurement showed that the sound level was higher $(\mathrm{Leq}=67.88 \mathrm{~dB})$ than the required level of $50 \mathrm{~dB}$. The M04 measurement in Ahmed Said Street, which has vending machine workers, and which is attached to a residential area with commercial activities, was higher $(74.81 \mathrm{~dB})$ than the required level of $50 \mathrm{~dB}$, and in $\mathrm{M} 05$, the sound level was also higher than the required level at $75.54 \mathrm{~dB}$. Figure 7 shows the time history Leq(A) and Leq(A) spectrum $1 / 3$ octave bands in each zone.

\subsection{Solar Radiation and Heat Island Results}

The solar radiation and UHI analyses found workers at the study area exposed to heat at several places: Ahmed Said Garage, El-Gesh Square, and Al-Abassya Youth Centre (Figure 8). A common feature of these three places was large open areas of asphalt and concrete. The asphalt had a low albedo value of 0.125 [56]. As Ahmed Said Garage has a massive area of asphalt for vehicle parking, both the asphalt area and the vehicles store heat and re-emit it, which creates a heat island effect. The precast concrete used in the youth center playground plays a significant role in increasing the zone's surface temperature and UHI effect, as the albedo value of the concrete was 0.25. Finally, El-Gesh Square is an 
open asphalt space and suffers from traffic congestion, both factors in increasing its surface temperature.

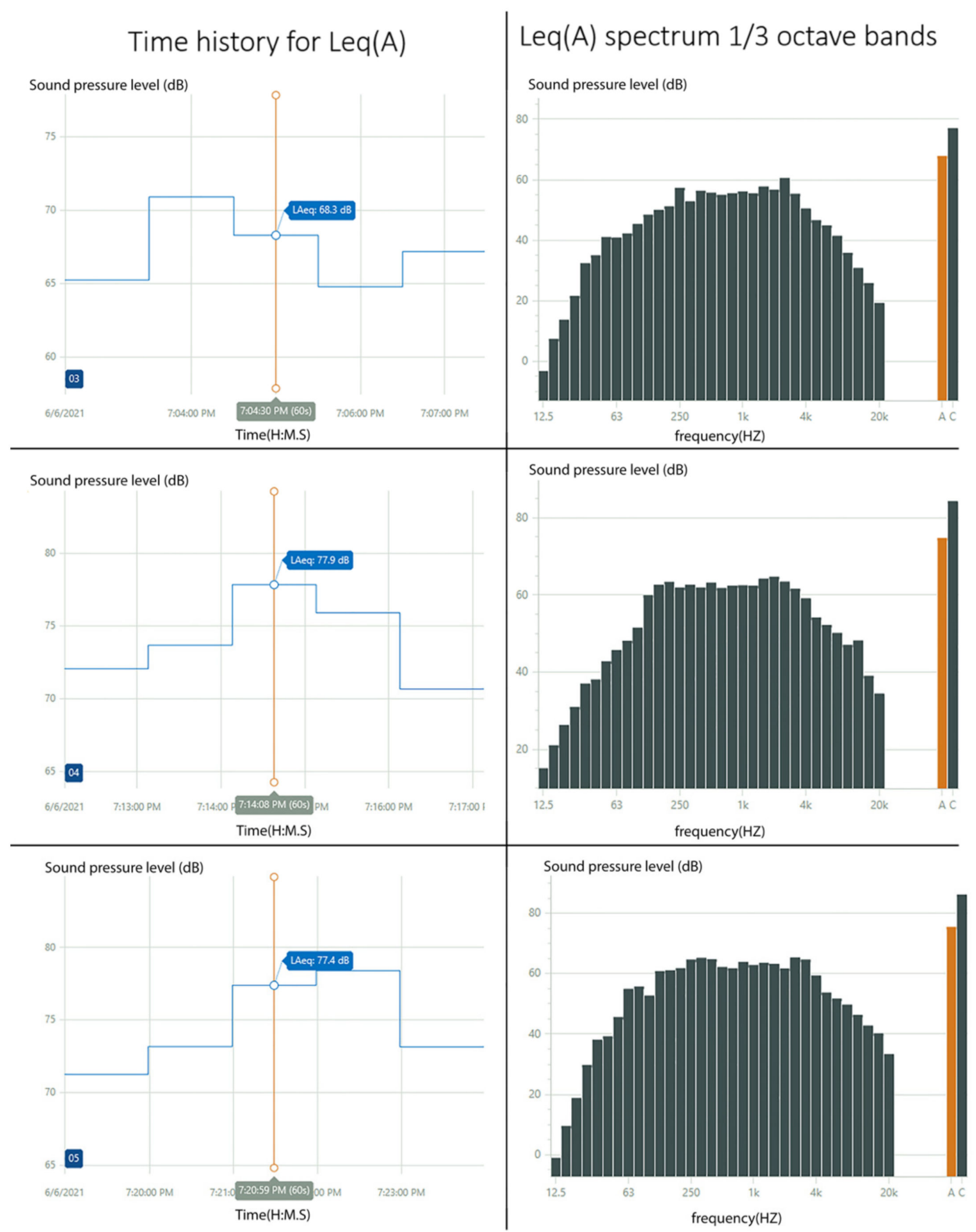

Figure 7. Time history for the Leq(A) and Leq(A) spectrum 1/3 octave bands in M03, M04, and M05. 


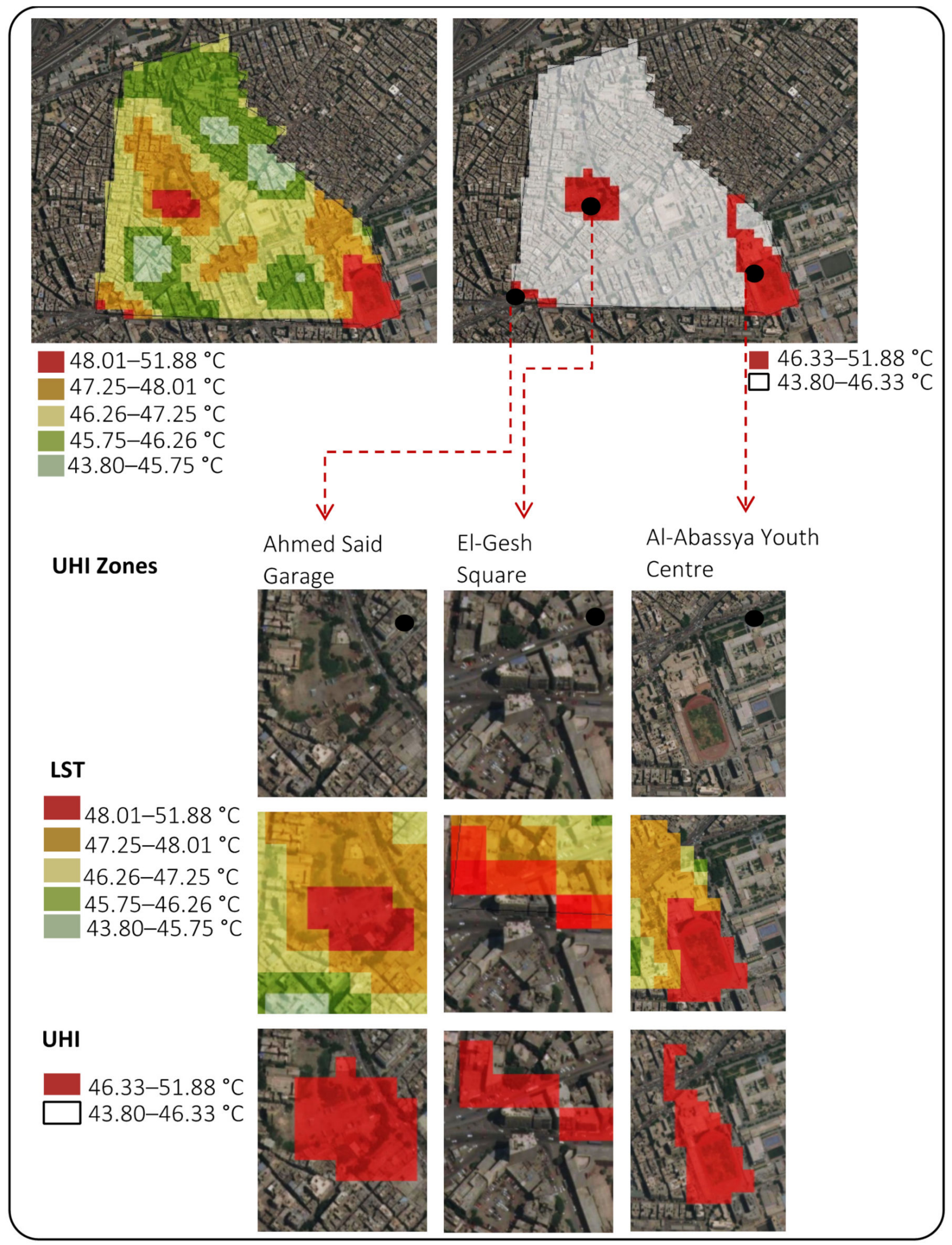

Figure 8. LST and UHI spots in the context adjacent to Ahmed Said Street.

Hence, the three spots of UHI found in the study area were open spaces characterized by low albedo materials that act as solar heat absorbers and raise the surface temperatures 
in comparison with the other land parcels in our selected case boundaries. These results were the same as the results from Grasshopper, where it was found that in the Ahmed Said Garage area and all other areas with outdoor workers, there was a high percentage of heat tolerance (Figure 9). The weather profile for 6 June 2021 indicated the lengths of time that the outdoor workers were exposed to the sun. The preliminary results indicated that the outdoor environment was not suitable for outdoor work. However, the compact urban fabric in the selected areas helped reduce the surface heat temperature.
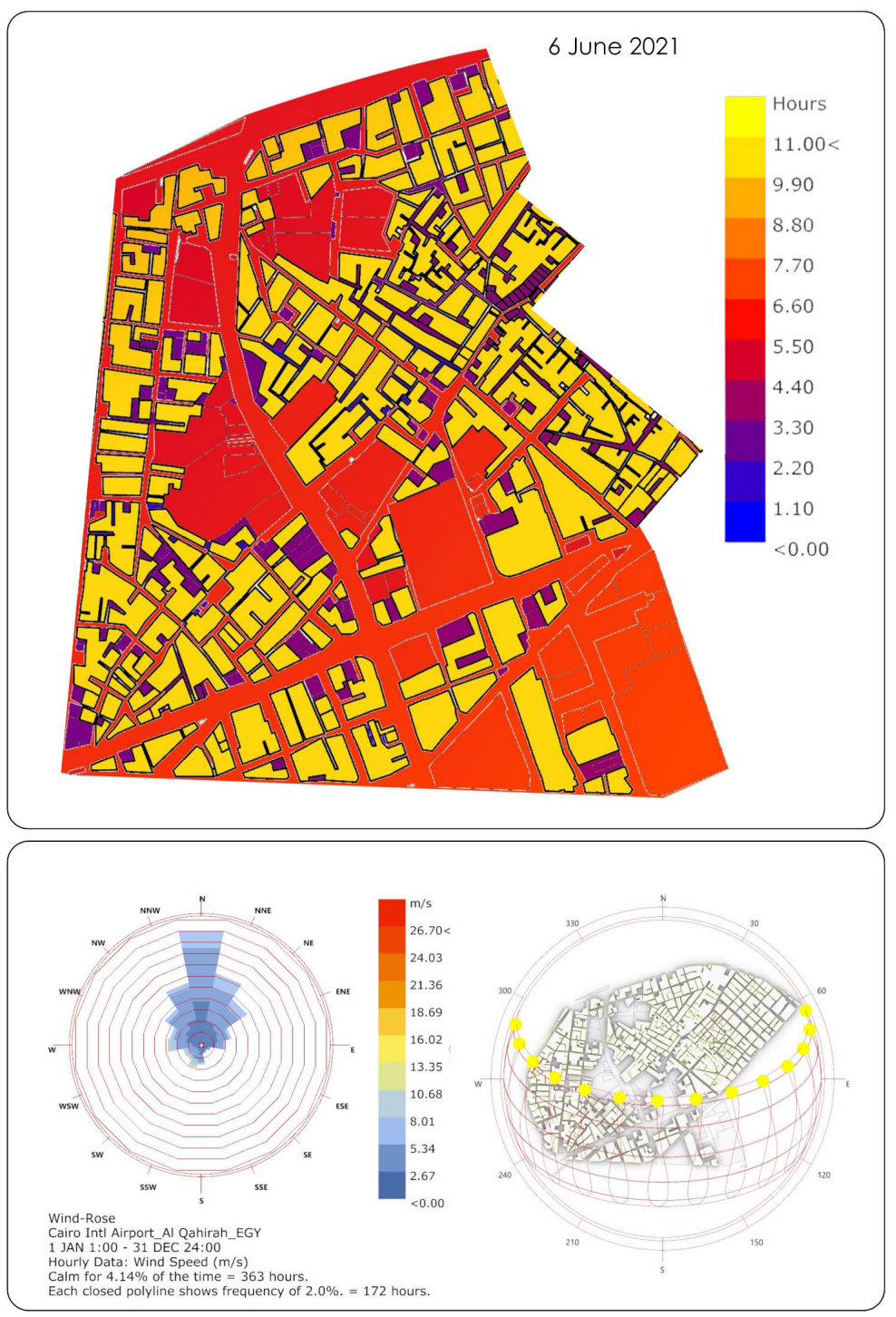

Figure 9. Winds and time durations during which the sites were exposed to solar heat on 6 June 2021.

\subsection{Results from Participant Observations}

The results from investigating participants' observations in the case study were built upon three groups of questions illustrated in a previous section of this manuscript. The first set of questions assisted the authors in determining the sample size and developing arguments based on their observations of the case study's outdoor workers. Here, we presented the results from the second and third groups of questions.

The results from the 77 participant observations in the first group of questions revealed that the main workers in the area were kiosk sellers (58 observations), vendors (33), traffic officers (31), sellers of ready-to-eat food (27), site construction workers (26), mechanics (27), and street workers (11). Forty-three observers found the workers neither satisfied nor dissatisfied, and 19 reported that the workers were dissatisfied. Two and 12 observers 
found that workers were pleased and intensely satisfied, respectively, and 1 identified depressed workers.

In the second group of questions, first, one of the questions asked the participants to rate the factors affecting workers' satisfaction while doing their jobs in the outdoor environments. The factors that affected worker productivity were identified as environmental factors, such as the local climate and tolerance, physical characteristics, and surroundings, such as "buildings and construction", social factors, such as "connectivity with peers or customers", and working hours, such as "time spent at work, work breaks, and the time when work starts in the early morning or afternoon." Seventy-three responses rated the environmental factors as those most affecting productivity, with a standard deviation (SD) of 1.11, and 76 responses $(\mathrm{SD}=1.01)$ rated physical characteristics as a minor factor affecting productivity. Seventy-five responses rated work hours with $\mathrm{SD}=1.07$, and 74 responses rated the social aspects $(\mathrm{SD}=1.08)$ (Figure 10).

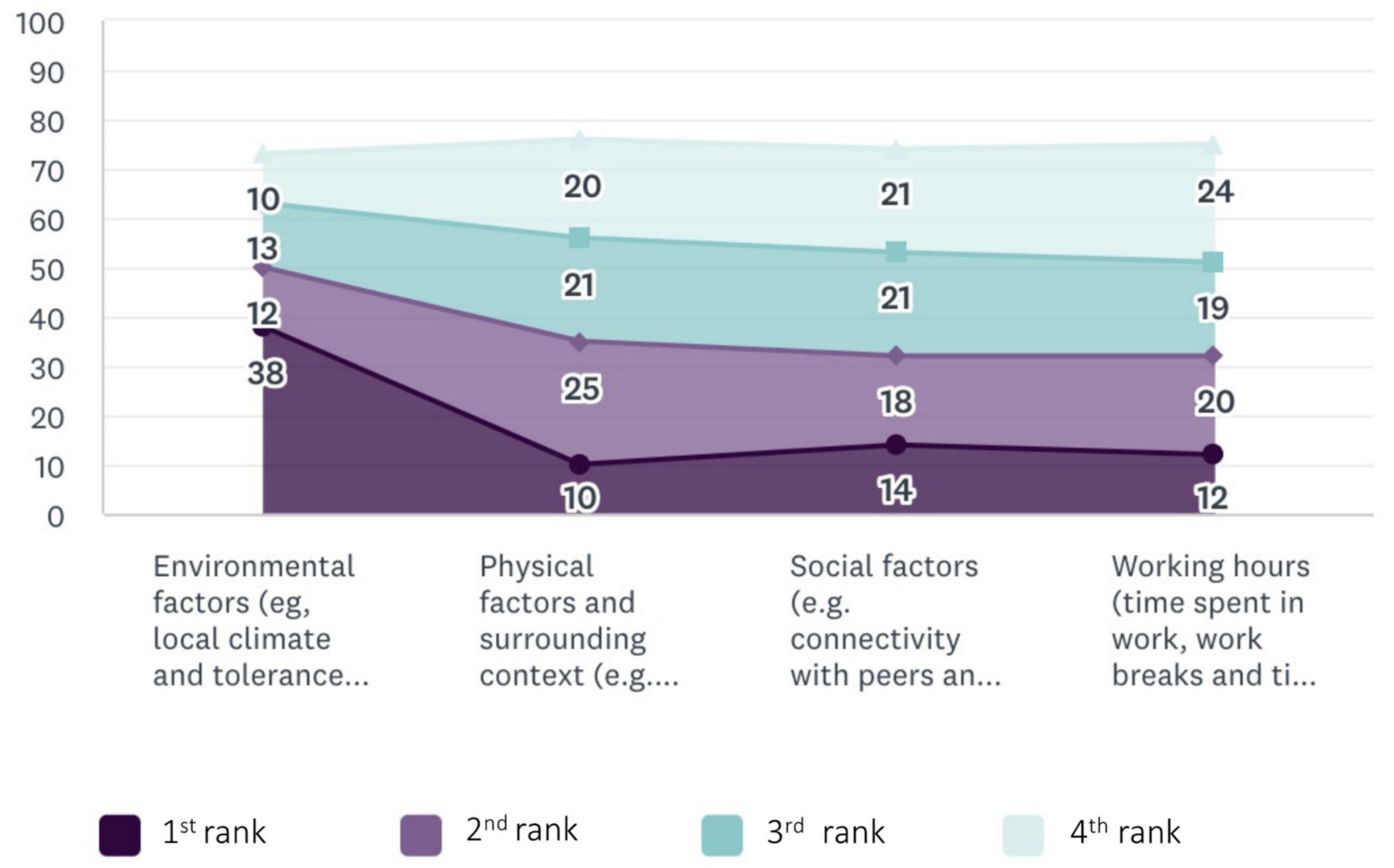

Figure 10. Factors affecting worker satisfaction.

Second, the participants were asked to specify the extent to which the workers were satisfied with the external environment for the following issues. Participants were able to leave the question blank if the item is not applicable. The observers were asked to specify the workers' satisfaction on the basis of their observation of workers on DOE. Thirty-eight percent found workers dissatisfied and very dissatisfied with their everyday life experiences while doing business, $38 \%$ found workers neither satisfied nor dissatisfied, $17 \%$ found the workers satisfied, and $5 \%$ found the workers depressed. The SD for "how enjoyable everyday life experience was while doing business" was 0.86 . In responding to "how pleasant and decent the outside environment is", $43 \%$ found the workers dissatisfied with the outdoor environment, $25 \%$ found the workers neither satisfied nor dissatisfied, $18 \%$ found the workers depressed, and $14 \%$ found the workers satisfied. The calmness investigation found $40 \%$ of the workers dissatisfied with the noise, $27 \%$ very dissatisfied, 
$26 \%$ neither satisfied nor dissatisfied, and 6\% happy. The SD for calmness was 0.88 . When asked about the availability of shade and shelter, $34 \%$ said the workers were neither satisfied nor dissatisfied, 29\% said that the workers were dissatisfied, 19\% said that the workers were very dissatisfied, $16 \%$ said that the workers were satisfied, and $3 \%$ said that the workers were happy $(\mathrm{SD}=1.05)$. The last indicator asked about how satisfied the workers were with their working time after sunset or late in the morning, to which $41 \%$ said that the workers were neither satisfied nor dissatisfied, 24\% said that the workers were satisfied, $23 \%$ said that the workers were dissatisfied, $5 \%$ said that the workers were very satisfied, and $7 \%$ said that the workers were very dissatisfied. Figure 11 shows the percentages for the factors affecting DOE.

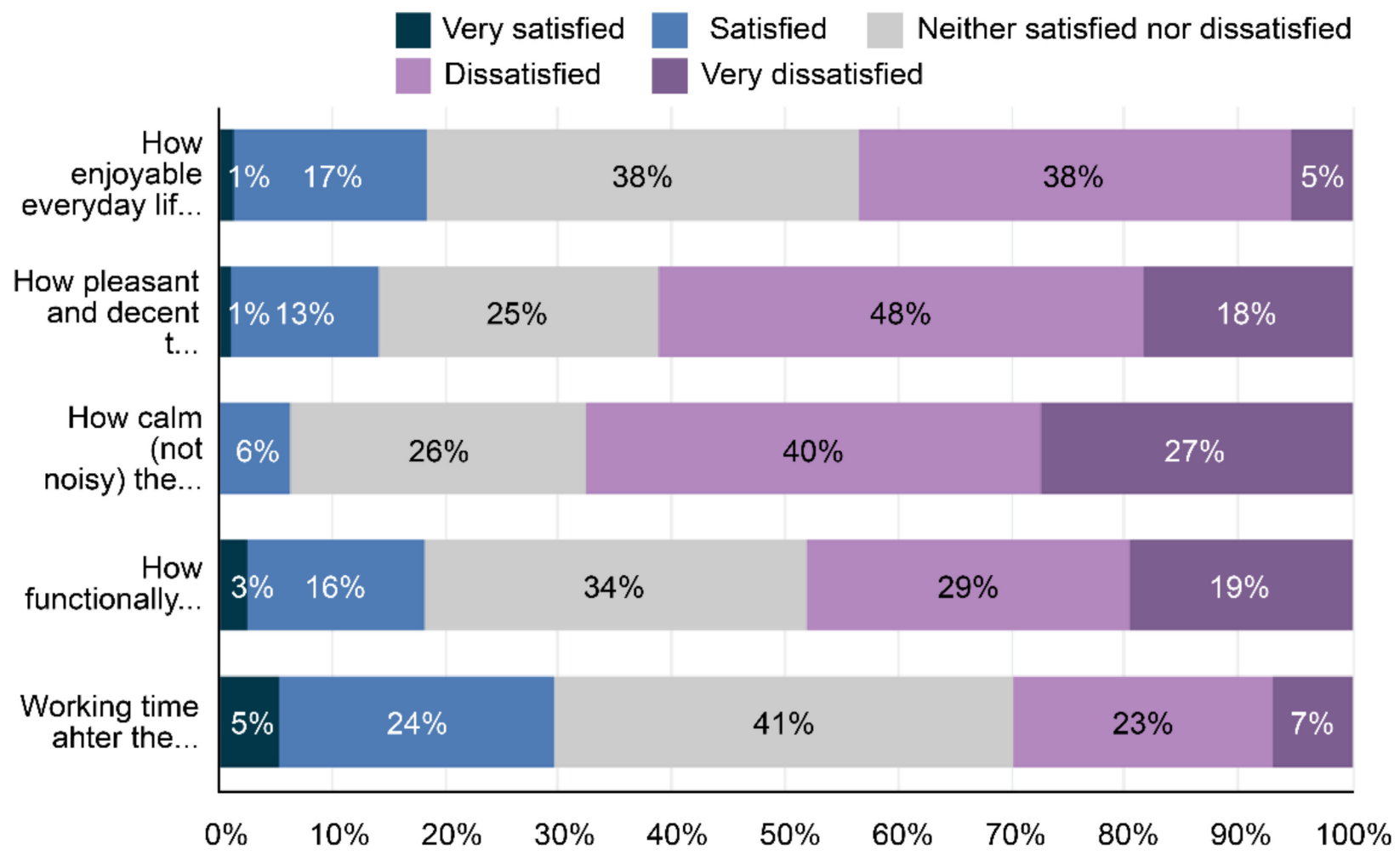

Figure 11. The satisfaction percentage for DOE.

Third, the participants were asked to specify the observed workers' satisfaction with SMTC. In the SMTC assessment, the majority of workers were neither satisfied nor dissatisfied. In this regard, 32 observations found either satisfaction or disaffection with the building facades, architecture, and the presence of architectural symbols on worker satisfaction. Thirty responses out of 77 found the workers either satisfied or dissatisfied with the reputation of everyday life experience. However, a few (13 responses) workers were neither satisfied nor dissatisfied with the level of technology in their work. The types of uses available at the site received 36 responses for either satisfaction or dissatisfaction. The robustness of the architecture system and the types of uses and amenities that can be found during the workers' break received 29 and 21 responses of either satisfaction or dissatisfaction, respectively. Similarly, 15 and 30 responses noted dissatisfaction or satisfaction toward the places of activities and legibility, respectively. Figure 12 shows all statistics for the morphological factor investigation and its effects on worker productivity. 


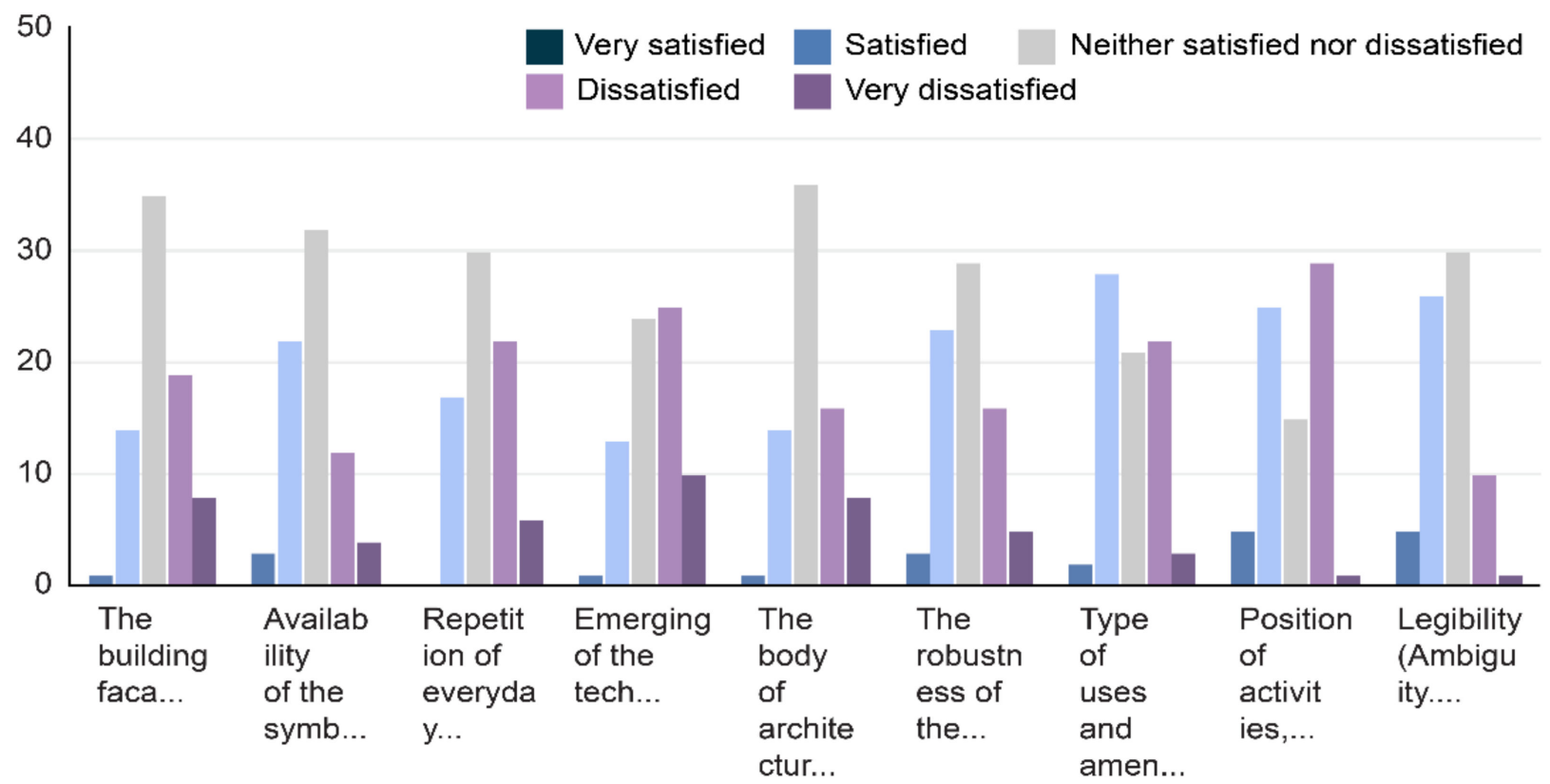

Figure 12. Worker satisfaction with the morphological factors.

Fourth, one of the roles of participant-observers is to identify the workers' satisfaction with regard to the intangible elements (RII) based on their discussions with them. The intangible indicator factors and subfactors affecting worker productivity were identified as comfort and mood, visual appropriateness, safety and security, livability, and the application of safety regulations. A high percentage expressed dissatisfaction with comfort (32 responses), convenient temperatures (36 responses), and a moderate number $(20,21$, and 30 responses, respectively), found dissatisfaction with the business sites, feeling safe, and the additive capacity for the workers' business. A low number of observers recorded satisfaction with the intangible indicators: 11 for comfort, 18 for pride, 28 for clear site imageability, and 22 for feeling safe and secure. Figure 13 shows the effects of intangible factors on worker productivity.

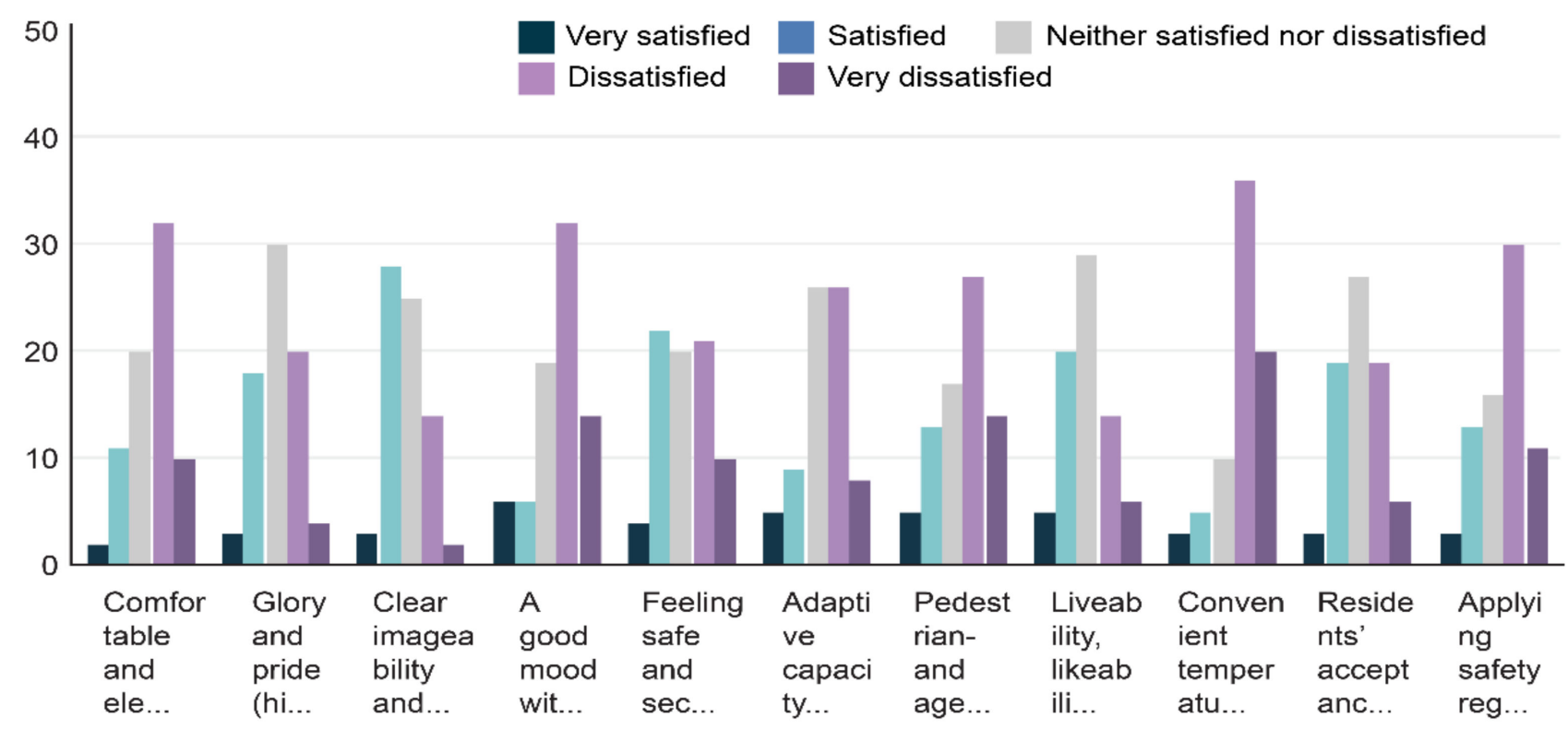

Figure 13. Results of RII. 
The third group of questions held three questions to let the participants add their feedback about the responses. In line with the various reasons for dissatisfaction with DOE, RII, and SMTC on the site, the observers commented as to whether they would recommend the business area to their peers. Figure 14 shows that user satisfaction toward the products and services provided on the site received a -76 net promoter score (NPS). This was compared with the SurveyMonkey Global benchmark of 51.2 NPS with a lower quartile of 20 and an upper quartile of 75.2 based on an investigation of 130,516 organizations with similar businesses on 6 June 2021.

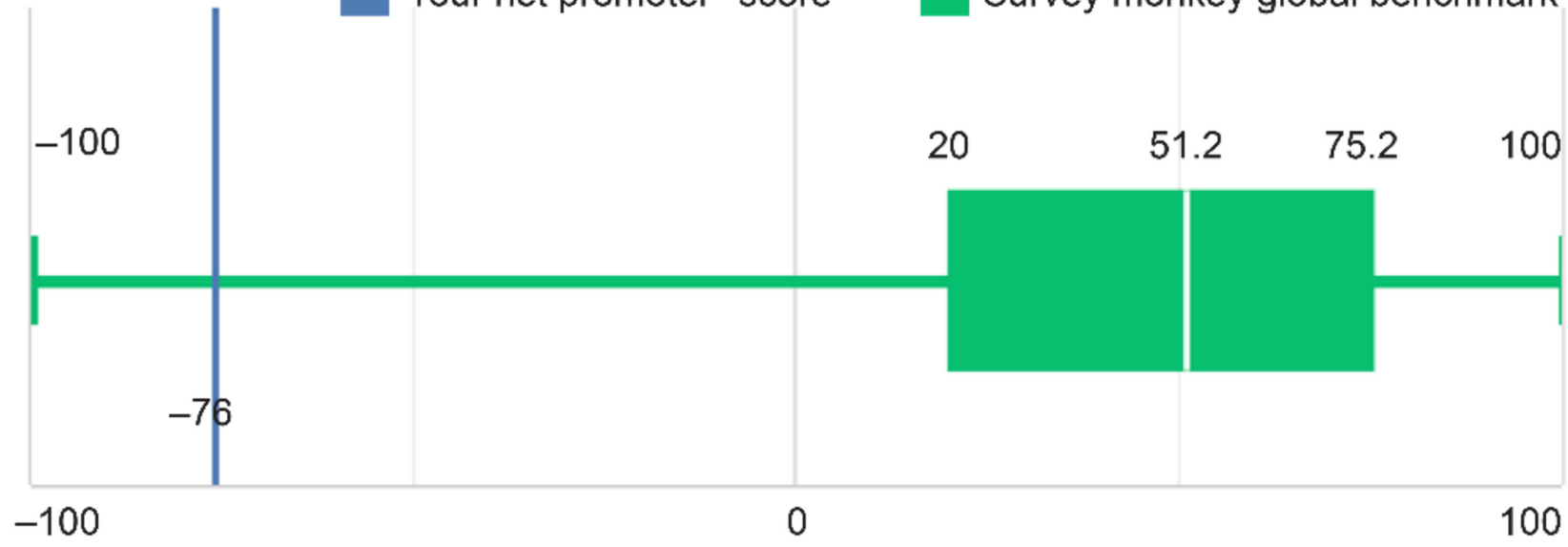

Figure 14. NPS for the workers' satisfaction compared to the SurveyMonkey benchmark.

Thus, the observer response indicators showed that several observers were dissatisfied with the workers' situations. Figure 15 shows the dissatisfaction with the mode, journey, safety from crime, and availability of amenities. In the open-ended questions, some observers mentioned that worker satisfaction with the surrounding environment stemmed, not from the availability of work for decades, but the fear and dread of elimination. This observation might have affected the response to the other factors that might have affected their productivity; however, some observations commented on the importance of the atmosphere on the workers' performance during working hours.

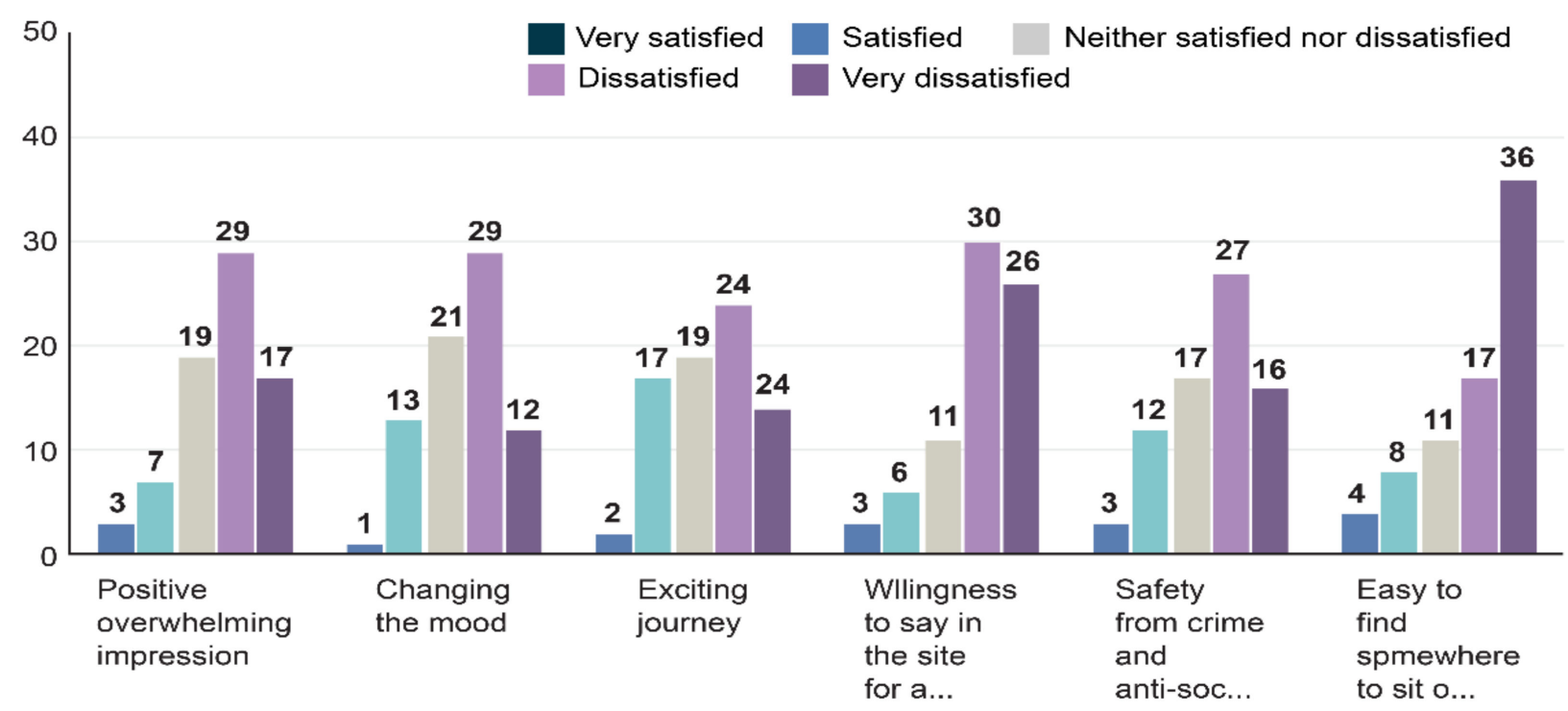

Figure 15. Observer response indicator results. 


\section{Discussion and Practical Implications}

It has been argued that urban design must also focus on the provision of places that enhance the ability of all-natural systems to withstand heat and sound effects $[34,61]$. With a particular focus on how urban planners and designers can use specific factors to develop suitable environmental places, this study used environmental methods to measure SPL and UHI in a case study on Al-Weili District, Cairo, Egypt and used a participant observation technique to investigate outdoor worker satisfaction with this site. We sought to identify how well Cairo's outdoor workers are satisfied with their work and how this satisfaction is affected by tangible environmental and socio-morphological factors.

Using quadrilateral data processing, a list of the factors that affect worker productivity (Figure 16) was extracted from relevant literature, which was grouped into environmental, planning, and design factors for the case study.

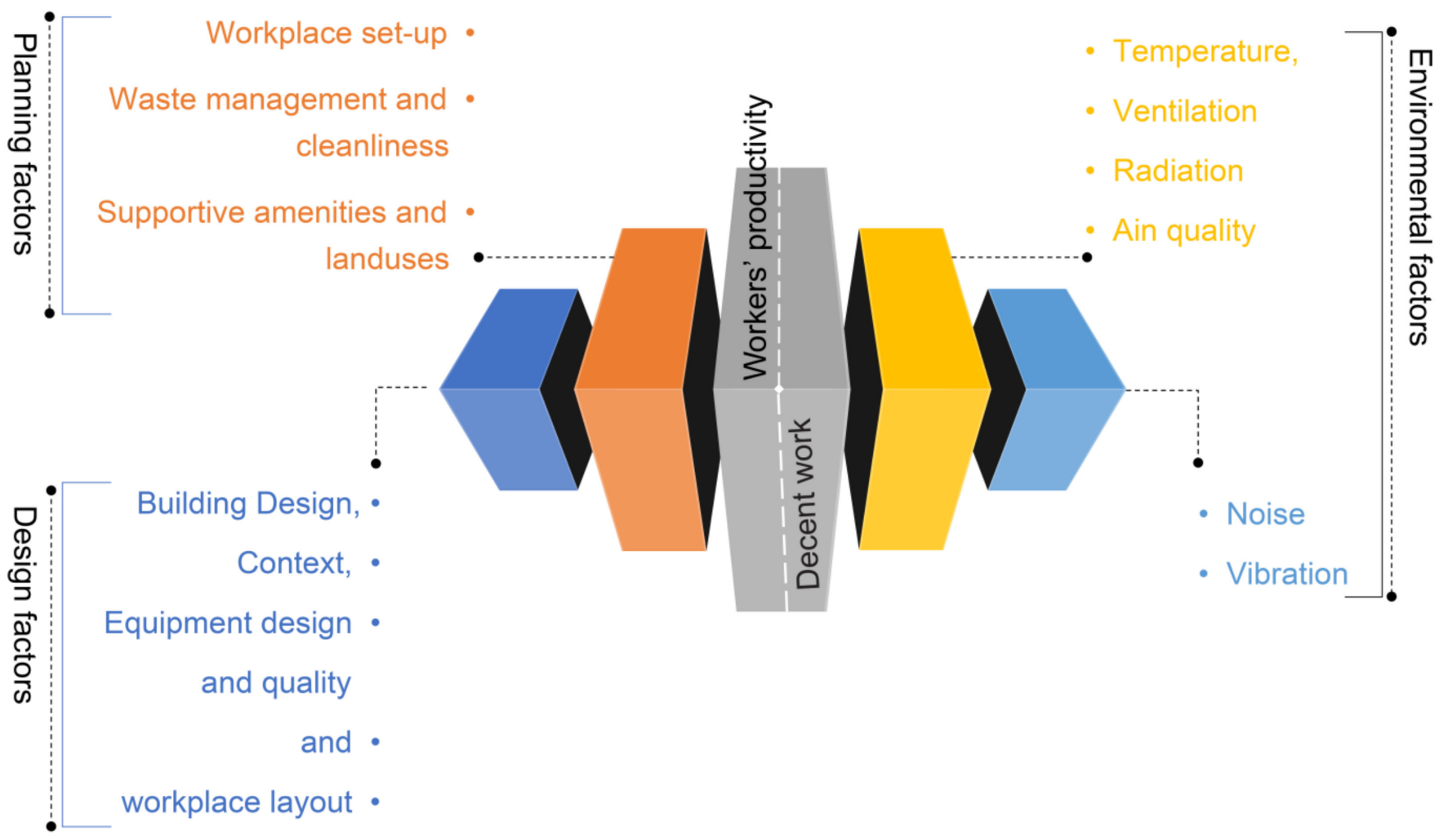

Figure 16. Factors affecting workers' productivity.

Two different approaches were used to address this study's urban planning and design research questions on outdoor worker satisfaction. Because the bibliometric search on the SJR database found a lack of ethnographic studies on the decent work addressed in SDG 8, the first approach used tools to measure the heat and sound tolerances that could affect decent work conditions and worker efficiency, and the effect UHI can have on livelihoods. Similarly, Barnett (2020) [61] and Hassan and Elkhateeb (2021) [35] confirmed the crucial role landslide prevention had on protecting natural systems from the effects of climate change and how landscaping and reconstruction could be applied to increase overall system capacity to deal with climate pressures. This study extended Barnett's [61] research to examine the challenges faced by workers from noise, heat, and external contextual factors. This approach can assist designers and planners in better facilitating productivity by selecting proper materials, locations, urban forms, configurations, and construction systems needed to decrease heat and noise stress.

The second approach was an ethnographic study to specifically examine the human challenges. Although several studies have examined user satisfaction with place designs 
and configuration $[30,35,62,63]$, few of the many studies on UHI, noise stress, and contextual effects have examined the workers' abilities to withstand the effects of the built environment.

The present literature review revealed the importance of paying attention to worker productivity in built environments. The results of the ethnographic analysis and field measurements highlighted the importance of considering three urban planning and design dimensions: DOEs, the SMTC, and user RII.

The results of this study confirmed the importance of aggregating the two approaches when seeking to holistically design places that provide decent outdoor work conditions and suggested that the 12 SDG 8 targets that facilitate decent work and productive employment can be extended [23]. Workers in outdoor environments are exposed to sound and heat stresses higher than the required level of $50 \mathrm{~dB}$ for residential areas on the decibel scale [25]. As suggested in previous studies $[8,35]$, this study's results also imply that greater focus must be placed on designs that consider different job types and support worker productivity. Therefore, special attention could be placed on updating the SDG 8 targets to design better workplaces that can raise worker productivity and satisfaction for people required to do outdoor jobs, such as construction workers, mechanics, and vendors.

This study took two approaches that could inform urban policies to support decent work environments and the urban forms that could increase worker productivity and satisfaction. A broad selection of current methods was applied to investigate the challenges outdoor workers face. Therefore, the main conclusion from this study is to update the SDG 8 targets to ensure that all types of workers are covered. The results from this study were in line with previous studies that examined the effects of urban atmosphere and users' emotional feelings about perceived quality in work and non-workplaces $[34,64,65]$. The affective work domain and front-line factors such as the working atmospheres and the surrounding contexts all have a direct influence on worker productivity. These results supplement those of previous studies that have found environmental and contextual factors as affecting workers' productivity in both outdoor and indoor places [54,66,67].

This study confirmed that worker satisfaction was affected by DOE, SMTC, and RII. However, the qualitative data analysis responses indicated that the workers were willing to make do with the outdoor environments when they had no other alternatives. Most observers noticed that although the workers were neither satisfied nor dissatisfied with the external contexts that might have affected their satisfaction, selecting the proper place for every single user needs to be carefully addressed because only relying on users' opinions about the location, materials, and timing ignores the people who might work in these environments. This suggestion is in line with previous studies that have highlighted the importance of the planning and design of the outdoor environment performance criteria $[27,61,68-70]$.

It was concluded that the workers' satisfaction with their workplace in terms of the support services, amenities, and other benefits influenced business quality, which was in line with previous research that confirmed that decent work strategies should be contextually reviewed $[60,71]$. Thus, the street worker livability dimensions are perhaps more important than the provision of work opportunities.

These findings have two socio-morphological, environmental, and policy implications for academia and professional practice and for follow-up on the SDG 8 targets. To encourage more robust discussions on soundscapes and climate-friendly developments for workers, two possible weak and strong sustainability policy pathways are suggested. In weak sustainability situations, practitioners in the economic and environmental domains should consider user job preferences. Academically, urban design studios stand to benefit from generating ideas from user experiences. Ethnographic studies also provide a platform to explore worker efficiency issues. In strong sustainability situations, the environmental aspects could be fully reviewed. The results from the Egyptian case study provide evidence that tracking decent work for human capital can go hand in hand with natural capital using mixed methods that aggregate UHI and sound stress with workers' satisfaction. 
This study was limited because the estimation of workers' satisfaction was only based on the effect of context on their performance, which should be in line with the economy and the workers' incomes. Two other limitations were collecting the weather and sound profiles using a limited number of heat and sound measurements only during Spring 2021. This could be extended to include field measurements for the case study during Summer, Winter, and Fall and comparing the results. In this regard, the study was limited to choosing one day as a sample and a duration of 5 minutes in 3 locations to collect sound profiles from the site. Additionally, the time used to estimate the SPL did not match with the time of the satellite images. The reason is that Landsat 8 produces images of Cairo in the morning when the noise on the site is not at its peak point. Previous research on this site indicates that most activities on the site occur at times closer to sunset [35]. Further, this study was limited in its use of participant observations to investigate worker satisfaction.

Finally, applying strong or weak sustainability discourses to different policy destinations has been proven to be successful $[27,72]$. The radical societal transformations needed to realize strong sustainability are more difficult to bring about than improving socioeconomic conditions. This analysis demonstrated that the solution to this challenge lies in combining the two strong and weak sustainability perspectives; however, the aim of this discussion was not to reach a conclusion; rather, it sought to foster debate on the assessment of worker productivity in difficult situations.

\section{Conclusions}

This study concludes by reviewing outdoor workers' satisfaction and factors affecting decent work. The literature review using bibliometric analysis provided some perspectives on the various factors that can affect decent work, such as the environment, design, and management trinity. The bibliometric analysis for the manuscript published between 2016 and 2021 figured out the factors affecting outdoor workers' satisfaction. The review of the selected manuscripts identified that when compared with the massive amount of research on workers in indoor environments, there existed a paucity of research, that is, a gap in research, on workers in outdoor environments. This generated the theoretical conclusion that achieving decent work as one of the sustainability goals specified in SDG 8 should be focused on both indoor and outdoor contexts.

In the case study, two investigative approaches were used in this study-digital measurements and an ethnographic study - to identify the factors affecting street worker productivity. The case study analysis revealed that when seeking to ensure the provision of decent work for street workers, environmental, management, and design factors all need to be considered. As discussed, as the morphology of cities could be promising for creating decent work, there is a need for proper indoor and outdoor urban forms and configurations to be added to the SDG 8 targets.

This research sheds light on the significance of addressing weak sustainability alongside strong sustainability. The findings provide two implications for SDG8 by putting workers' satisfaction in mind while creating decent work. The first is the practical implication of the targets of SDG8 by considering the preference of outdoor workers through socio-morphological and environmental aspects of workers' responses to these aspects. The second implication is that urban design studios might benefit academically by drawing on real-world experiences to develop new concepts for designing better places for people who work in outdoor environments. Ethnographic research may also be used to investigate workplace efficiency concerns. It is possible to do a complete environmental assessment when there is a high degree of sustainability. In the Egyptian case study, the findings show that monitoring decent work for human capital may go hand in hand with natural capital, utilizing diverse approaches that aggregate UHI and sound stress with workers' contentment.

Because of the limited case study data, case investigations could not be conducted in other outdoor worker locations in Al-Weili and other locations in Cairo. The limitation in collecting data on the sound profile for one day can be extended in future studies to 
measure sound pulsion across various days. Future research could consider the dimensions that affect decent work, such as employment opportunities. Future research could also consider managerial factors, such as decent hours and work-life balance. Lunch surveys at kiosks or online surveys in working communities could also provide more insights into these managerial factors.

Author Contributions: Conceptualization, A.E. and H.A.; methodology, A.E.; software, A.E., A.A., N.E.-B., E.E. and S.G.; formal analysis, A.E., H.A., A.A., N.E.-B. and S.G.; data curation, A.E. and H.A.; review and editing, A.E. and H.A.; visualization, A.E. and A.A.; project administration, A.E.; funding acquisition, A.E. All authors have read and agreed to the published version of the manuscript.

Funding: The study was supported by a grant from The Science, Technology, and Innovation Funding Authority (STDF) under grant number [STDF-BARG 37234].

Institutional Review Board Statement: This study was conducted in accordance with the Declaration of Helsinki, and approved by both Ain Shams University and Science, Technology, and Innovation Funding Authority. The approval included conducting ethnographic research about urban morphology and urban heat islands in Cairo. The approval was received to the principal investigator (PI), AE, on 23 November 2020 (date of signing the funded project contract by my affiliated university and the Science, Technology, and Innovation Funding Authority). The crossponding author also confirm that Ain Shams University does not establish Institutional Review Board (IRB) at the moment of conducting the current study.

Informed Consent Statement: The identities of the 77 students who showed up willing to participate in our ethnographic study are anonymous. We confirm that all volunteer participants confirmed their willingness to take part in this study prior to filling out the survey form. So, informed consent was obtained from all participants involved in the study.

Data Availability Statement: The data presented in this study are openly available in FigShare at https:/ / doi.org/10.6084/m9.figshare.17910827.v2 (accessed on 10 September 2021).

Acknowledgments: We would like to thank all participants for giving their time to take part in our ethnographic research of March-June 2021.

Conflicts of Interest: There are no conflicts of interest to declare.

Declaration: The current work applies compliance with ethical standards in the following:

- Disclosure of potential conflicts of interest: The authors of the present study declare that they have no conflicts of interest.

- Research Involving Human Participants and or Animals: There is no research involving animals. Regarding Human Participants, the researchers of the current study used volunteer participants (77 out of 123 students) in the authors' classes during Spring 2021.

- Data collection and analysis: The authors confirm that the results presented in this study were mainly prepared for this research during the years 2020 and 2021. There is no similarity in research design or results that could be found between any previous research conducted by the authors of the present work or anybody else.

- $\quad$ Ethics Statement: Approval for the study was not required in accordance with local/national legislation.

\section{References}

1. Chang, J.-H. Thermal comfort and climatic design in the tropics: An historical critique. J. Arch. 2016, 21, 1171-1202. [CrossRef]

2. Clark, S.N.; Alli, A.S.; Nathvani, R.; Hughes, A.; Ezzati, M.; Brauer, M.; Toledano, M.B.; Baumgartner, J.; Bennett, J.E.; Nimo, J.; et al. Space-time characterization of community noise and sound sources in Accra, Ghana. Sci. Rep. 2021, 11, 1-14. [CrossRef] [PubMed]

3. Martins, J. Work in and for a healthy city. Urban Des. Int. 2021, 26, 117-121. [CrossRef]

4. Oke, T.; Mills, G.; Christen, A.; Voogt, J. Urban Climates; Cabridge University Press: Cabridge, UK, 2017.

5. Shandas, V.; Skelhorn, C.; Ferwati, S. Urban Adaptation to Climate Change: The Role of Urban Form in Mediating Rising Temperatures; Springer Nature: Cham, Switzerland, 2020.

6. Afshari, A.; Ramirez, N. Improving the accuracy of simplified urban canopy models for arid regions using site-specific prior information. Urban Clim. 2021, 35, 100722. [CrossRef] 
7. Dunne, J.P.; Stouffer, R.J.; John, J.G. Reductions in labour capacity from heat stress under climate warming. Nat. Clim. Chang. 2013, 3, 563-566. [CrossRef]

8. $\quad$ Fang, Z.; Tang, T.; Zheng, Z.; Zhou, X.; Liu, W.; Zhang, Y. Thermal responses of workers during summer: An outdoor investigation of construction sites in South China. Sustain. Cities Soc. 2021, 66, 102705. [CrossRef]

9. Gozalo, G.R.; Morillas, J.M.B.; González, D.M.; Moraga, P.A. Relationships among satisfaction, noise perception, and use of urban green spaces. Sci. Total Environ. 2018, 624, 438-450. [CrossRef]

10. Huimin, L.; Junjie, Q.; Hui, H. Explore which industries are suitable for open office: Through an experiment on the impact of noise on individual job performance. Noise Control Eng. J. 2019, 67, 422-437. [CrossRef]

11. Haddad, M.A.; Hellyer, J. Decent Work and Social Protection in Belo Horizonte, Brazil. J. Plan. Educ. Res. 2018, 38, 86-97. [CrossRef]

12. International Labour Organization (ILO). Goal 8: Promote Inclusive and Sustainable Economic Growth, Employment and Decent Work for All. 2015. Available online: https://www.ilo.org/global/topics/dw4sd/theme-by-sdg-targets/WCMS_556964/lang-en/index.htm (accessed on 10 September 2021).

13. Anjos, M.; Targino, A.C.; Krecl, P.; Oukawa, G.Y.; Braga, R.F. Analysis of the urban heat island under different synoptic patterns using local climate zones. Build. Environ. 2020, 185, 107268. [CrossRef]

14. Dixit, S.; Mandal, S.N.; Thanikal, J.V.; Saurabh, K. Evolution of studies in construction productivity: A systematic literature review (2006-2017). Ain Shams Eng. J. 2019, 10, 555-564. [CrossRef]

15. Anker, R.; Chernyshev, I.; Egger, P.; Mehran, F.; Ritter, J.A. Measuring decent work with statistical indicators. Int. Labour Rev. 2003, 142, 147-178. [CrossRef]

16. Bonafoni, S.; Baldinelli, G.; Verducci, P. Sustainable strategies for smart cities: Analysis of the town development effect on surface urban heat island through remote sensing methodologies. Sustain. Cities Soc. 2017, 29, 211-218. [CrossRef]

17. Liu, H.; Hu, T. How does air quality affect residents' life satisfaction? Evidence based on multiperiod follow-up survey data of 122 cities in China. Environ. Sci. Pollut. Res. 2021, 28, 61047-61060. [CrossRef] [PubMed]

18. Wheatley, D. Workplace location and the quality of work: The case of urban-based workers in the UK. Urban Stud. 2021, 58, 2233-2257. [CrossRef]

19. Monazzam, M.R.; Abolhasannejad, V.; Moasheri, B.N.; Abolhasannejad, V.; Kardanmoghaddam, H. Noise pollution in old and new urban fabric with focus on traffic flow. J. Low Freq. Noise Vib. Act. Control. 2016, 35, 257-263. [CrossRef]

20. Wu, W.; Chen, Y.; Stephens, M.; Liu, Y. Long working hours and self-rated health: Evidence from Beijing, China. Cities 2019, 95, 1-9. [CrossRef]

21. Xia, Y.; Li, Y.; Guan, D.; Tinoco, D.M.; Xia, J.; Yan, Z.; Yang, J.; Liu, Q.; Huo, H. Assessment of the economic impacts of heat waves: A case study of Nanjing, China. J. Clean. Prod. 2018, 171, 811-819. [CrossRef]

22. United Nations. The Sustainable Development Goals Report; United Nations: New York, NY, USA, 2021.

23. International Labor Organization (ILO). The 2030 Development Agenda. 2021. Available online: https://www.ilo.org/global/ topics/sdg-2030/goal-8/WCMS_403787/lang--en/index.htm (accessed on 31 June 2021).

24. Climate Change Vulnerability Assessment (CCVA). Appendix D: Urban Heat Island Protocol for Mapping Temperature Projections; Kleinfelder: Cambridge, UK, 2015.

25. Occupational Safety and Health Administration. OSHA Technical Manual (OTM); United States Department of Labor: Washington, DC, USA, 2019.

26. Ritchie, R.; Mispy, O. Measuring Progress towards the Sustainable Development Goals. SDG-Tracker.org. 2018. Available online: https://sdg-tracker.org/ (accessed on 31 June 2021).

27. Hasle, P.; Vang, J. Designing better interventions: Insights from research on decent work. J. Supply Chain Manag. 2021, 57, 58-70. [CrossRef]

28. Anner, M. Three labour governance mechanisms for addressing decent work deficits in global value chains. Int. Labour Rev. 2021, 160, 611-629. [CrossRef]

29. Austin, S.; Sharr, A. The University of Nonstop society: Campus planning, lounge space, and incessant productivity. Arch. Cult. 2021, 9, 69-97. [CrossRef]

30. Webster, E.; Budlender, D.; Orkin, M. Developing a diagnostic tool and policy instrument for the realization of decent work. Int. Labour Rev. 2015, 154, 123-145. [CrossRef]

31. Chokhachian, A.; Perini, K.; Giulini, S.; Auer, T. Urban performance and density: Generative study on interdependencies of urban form and environmental measures. Sustain. Cities Soc. 2020, 53, 1-14. [CrossRef]

32. Zare, S.; Hemmatjo, R.; ElahiShirvan, H.; Malekabad, A.; Ziaei, M.; Nadri, F. Evaluation of individual and environmental sound pessure level and drawing noise-Isosonic maps using surfer V.14 and noise at work V.5.0. Sound Vib. 2021, 55, $163-171$.

33. Palacios, J.; Eichholtz, P.; Kok, N. Moving to productivity: The benefits of healthy buildings. PLoS ONE 2020, 15, e0236029. [CrossRef]

34. Adams, D.; Smith, M.; Larkham, P.; Abidin, J. Encounters with a future past: Navigating the shifting urban atmospheres of place. J. Urban Des. 2020, 25, 308-327. [CrossRef]

35. Hassan, D.K.; Elkhateeb, A. Walking experience: Exploring the trilateral interrelation of walkability, temporal perception, and urban ambiance. Front. Arch. Res. 2021, 10, 516-539. [CrossRef] 
36. Park, G.; Evans, G.W. Environmental stressors, urban design and planning: Implications for human behaviour and health. J. Urban Des. 2016, 21, 453-470. [CrossRef]

37. Idkhan, A.; Baharuddin, F. Occupational health and productivity in noise exposure and room layout. Int. J. Sci. Technol. Res. 2019, $8,516-522$.

38. Liu, B.; Wu, J.; Chan, K.C. Does air pollution change a firm's business strategy for employing capital and labor? Bus. Strategy Environ. 2021, 30, 3671-3685. [CrossRef]

39. Nielsen, K.; Nielsen, M.B.; Saari, E.; Isaksson, K. Workplace resources to improve both employee well-being and performance: A systematic review and meta-analysis. Work. Stress Int. J. Work. Health Organ. 2017, 31, 101-120. [CrossRef]

40. Stauber, C.; Adams, E.A.; Rothenberg, R.; Dai, D.; Luo, R.; Weaver, S.R.; Prasad, A.; Kano, M.; Heath, J. Measuring the impact of environment on the health of large cities. Int. J. Environ. Res. Public Health 2018, 15, 1216. [CrossRef] [PubMed]

41. Maskooni, E.; Hashemi, H.; Berndtsson, R.; Arasteh, P.; Kazemi, M. Impact of spatiotemporal land-use and land-cover changes on surface urban heat islands in a semiarid region using Landsat data. Int. J. Digit. Earth 2020, 14, 250-270. [CrossRef]

42. Nwakaire, C.M.; Onn, C.C.; Yap, S.P.; Yuen, C.W.; Onodagu, P.D. Urban heat island studies with emphasis on urban pavements: A review. Sustain. Cities Soc. 2020, 63, 1-20. [CrossRef]

43. Parker, J. The Leeds urban heat island and its implications for energy use and thermal comfort. Energy Build. 2021, $235,110636$. [CrossRef]

44. Silva, M.; Oliveira, V.; Leal, V. Urban morphology and energy: Progress and prospects. Urban Morphol. $2016,20,72-73$.

45. Yin, J.; Overpeck, J.; Peyser, C.; Stouffer, R. Big jump of record warm global mean surface temperature in 2014-2016 related to unusually large oceanic heat releases. Geophys. Res. Lett. 2018, 45, 1069-1078. [CrossRef]

46. Levanon, A.; Lavee, E.; Strier, R. Explaining the factors shaping the likelihood of poverty among working families by using a concurrent mixed method design. Soc. Indic. Res. 2021, 157, 1089-1109. [CrossRef]

47. Matović, N.; Ovesni, K. Interaction of quantitative and qualitative methodology in mixed methods research: Integration and/or combination. Int. J. Soc. Res. Methodol. 2021, 1-15. [CrossRef]

48. Ramzi, A.I. Evaluation feature extracting from DubaiSat-2 satellite images over planned/unplanned complex study area in Egypt. Ain Shams Eng. J. 2018, 9, 3371-3379. [CrossRef]

49. Science for a Changing World-USGS. Mapping, Remote Sensing, and Geospatial Data What Are the Band Designations for the Landsat Satellites? 2019. Available online: https:/ /www.usgs.gov/faqs/what-are-band-designations-landsat-satellites (accessed on 10 September 2021).

50. Rendenieks, Z.; Nita, M.D.; Nikodemus, O.; Radeloff, V.C. Half a century of forest cover change along the Latvian-Russian border captured by object-based image analysis of Corona and Landsat TM/OLI data. Remote Sens. Environ. 2020, 249, 112010. [CrossRef]

51. Athukorala, D.; Murayama, Y. Urban heat island formation in Greater Cairo: Spatiotemporal analysis of daytime and nighttime land surface temperatures along the urban-rural gradient. Remote Sens. 2021, 13, 1396. [CrossRef]

52. Mukherjee, S.; Joshi, P.K.; Garg, R.D. Analysis of urban built-up areas and surface urban heat island using downscaled MODIS derived land surface temperature data. Geocarto Int. 2017, 32, 900-918. [CrossRef]

53. Li, H.; Zhou, Y.; Li, X.; Meng, L.; Wang, X.; Wu, S.; Sodoudi, S. A new method to quantify surface urban heat island intensity. Sci. Total Environ. 2018, 624, 262-272. [CrossRef]

54. Zhou, B.; Lauwaet, D.; Hooyberghs, H.; De Ridder, K.; Kropp, J.; Rybski, D. Assessing seasonality in the surface urban heat island of London. J. Appl. Meteorol. Clim. 2016, 55, 493-505. [CrossRef]

55. Li, X. Investigating the spatial distribution of resident's outdoor heat exposure across neighborhoods of Philadelphia, Pennsylvania using urban microclimate modeling. Sustain. Cities Soc. 2021, 72, 1-9. [CrossRef]

56. Mohajerani, A.; Bakaric, J.; Jeffrey-Bailey, T. The urban heat island effect, its causes, and mitigation, with reference to the thermal properties of asphalt concrete. J. Environ. Manag. 2017, 197, 522-538. [CrossRef]

57. Xia, B.; Li, Z. Optimized methods for morphological design of mesoscale cities based on performance analysis: Taking the residential urban blocks as examples. Sustain. Cities Soc. 2021, 64, 102489. [CrossRef]

58. Ilbeigi, M.; Ghomeishi, M.; Dehghanbanadaki, A. Prediction and optimization of energy consumption in an office building using artificial neural network and a genetic algorithm. Sustain. Cities Soc. 2020, 61, 102325. [CrossRef]

59. Elbardisy, W.M.; Salheen, M.A.; Fahmy, M. Solar Irradiance Reduction Using Optimized Green Infrastructure in Arid Hot Regions: A Case Study in El-Nozha District, Cairo, Egypt. Sustainability 2021, 17, 9617. [CrossRef]

60. Smith, T.A.; Brown, A. Community-led housing and urban livelihoods: Measuring employment in low-income housing delivery. Habitat Int. 2019, 94, 102061. [CrossRef]

61. Barnett, J. Urban design for a warming climate: Where to build; when to build; what to build. J. Urban Des. 2020, 25, 3-5. [CrossRef]

62. De Araújo, L.O.C.; Caldas, C.; Tam, V.W.-Y. Reducing labor productivity losses through a productivity stratification indicator. J. Arch. Eng. 2021, 27, 04020044. [CrossRef]

63. Zhang, B.; Dong, H. User involvement in design: The four models. Lect. Notes Comput. Sci. 2016, 9754, 141-152. [CrossRef]

64. Stefansdottir, H. The role of urban atmosphere for non-work activity locations. J. Urban Des. 2018, 23, 319-335. [CrossRef]

65. Elmarakby, E.; Khalifa, M.; Elshater, A.; Afifi, S. Tailored methods for mapping urban heat islands in Greater Cairo Region. Ain Shams Eng. J. 2021, 13, 101545. [CrossRef] 
66. Niemelä, T.; Levy, K.; Kosonen, R.; Jokisalo, J. Cost-optimal renovation solutions to maximize environmental performance, indoor thermal conditions and productivity of office buildings in cold climate. Sustain. Cities Soc. 2017, 32, 417-434. [CrossRef]

67. Abusaada, H.; Elshater, A. Effect of people on placemaking and affective atmospheres in city streets. Ain Shams Eng. J. 2021, 12, 3389-3403. [CrossRef]

68. Ornstein, S.W. A postoccupancy evaluation of workplaces in Sao Paulo, Brazil. Environ. Behav. 1999, 31, 435-462. [CrossRef]

69. Xue, J.; Næss, P.; Stefansdottir, H.; Steffansen, R.; Richardson, T. The hidden side of Norwegian cabin fairytale: Climate implications of multi-dwelling lifestyle. Scand. J. Hosp. Tour. 2020, 20, 459-484. [CrossRef]

70. Abusaada, H.; Elshater, A. Improving visitor satisfaction in Egypt's Heliopolis historical district. J. Eng. Appl. Sci. 2021, 68, 1-22. [CrossRef]

71. Abusaada, H.; Elshater, A. Urban design assessment tools: A model for exploring atmospheres and situations. Proc. Inst. Civ. Eng.-Urban Des. Plan. 2021, 173, 238-255. [CrossRef]

72. Barua, A.; Khataniar, B. Strong or weak sustainability: A case study of emerging Asia. Asia-Pacific Dev. J. 2016, 22, 1-31. [CrossRef] 